
\title{
IJBF MODELLING THE BEHAVIOUR
OF TECHNICIANS AND FUNDAMENTALISTS IN THE SHANGHAI STOCK MARKET
}

\author{
Imad Moosa and Larry Li \\ Monash University and Latrobe University
}

\begin{abstract}
This paper provides empirical evidence on the role of fundamentalists and technicians in the Chinese stock market. Three econometric models are used to differentiate the stock price effect between the actions of traders who act on the basis of fundamental analysis and those acting on the basis of technical analysis. The models are estimated using randomly selected monthly and daily data on the stock prices of one hundred companies listed on the Shanghai Stock Exchange. The results reveal that both fundamentalists and technicians have roles to play in stock price formation, although technicians appear to play a more important role. This result holds even if the government intervention is allowed for. Some explanations are presented for the dominance of technicians.
\end{abstract}

Keywords: Technical analysis, Fundamentalists, Share prices, Shanghai exchange, Government intervention JEL Classification: D53, G24

\section{Introduction}

The objective of this paper is to present empirical evidence on the role played by fundamentalists and technicians, as market analysts, in the Shanghai stock market. The evidence is based on three versions of the model proposed by Moosa and Korczak (2000) and Moosa and Al-Loughani (2003), which follows, in part, the model proposed by Frankel and Froot (1990) to differentiate the roles played by fundamentalists and technicians in the foreign exchange market. The modification of the basic version of the model is takes into account two issues: (i) the possibility that the price effect measures may be sensitive to the specification of the reaction function of the technicians, and (ii) the role of government intervention in stock price determination, the latter being a potential factor in this 
market. The proposed models are estimated and tested using randomly selected time series data on the stock prices of one hundred Chinese companies covering two frequencies (daily and monthly) and various time periods.

The behaviour of traders who act on the basis of fundamental analysis and those who act on the basis of technical charting analysis may differ drastically. Fundamental analysts watch deviations from an equilibrium price, as implied by an assumed fundamental model. If the current price is above its equilibrium level, the asset is sold, which should lead to a decline in the price. This is not necessarily the case, however. If, by watching technician's charts or following quantitative technical indicators, technical analysts believe that there is no indication of a trend reversal, they will keep on buying the asset, lending support to the price. How the price moves depends on the net effect of the forces of supply and demand resulting from the actions of both fundamental analysts and technical analysts. The same argument is valid if the price falls below its equilibrium level.

Economists, who are essentially fundamentalists, have been studying technical analysis and the role of technicians with increasing enthusiasm, motivated by the desire to come up with an explanation for the deviation of financial prices from the values implied by fundamental models of financial price determination. In studying technical analysis, economists seek to address three issues: (i) the extent to which technical analysis is used in practice to predict price movements; (ii) the forecasting power of technical models as opposed to fundamental models; and (iii) the role played by technicians in financial price determination. While this study is concerned primarily with the third question, the empirical findings should shed some light on the other two issues. If, for example, the results indicate that the actions of technicians are more powerful in determining financial prices, we may conclude that (i) technical analysis must be used extensively, and (ii) the forecasting power of technical models is superior to that of fundamental models.

The rest of the paper is divided as follows. In the next section, the reader will find a brief review of relevant prior studies on the subject. In section 3 can be found the models to be used in this study. The findings are presented and commented upon in section 4 . The paper ends with a concluding final section.

\section{The Empirical Evidence}

Empirical evidence on the role played by fundamentalists and technicians in financial markets is found in studies following three approaches: (i) those based on econometric models; (ii) survey studies; and (iii) those analysing the comparative profitability of fundamental and technical trading rules.

One of the pioneering studies based on econometric modelling is that of Frankel and Froot (1990), who designed a model that is founded on the same idea to explain the sharp rise in the demand for the dollar in the first half of the 1980s. On the basis of the results produced by their model, they attributed the increase in the demand for the U.S. currency to the overwhelming role played 
by technical analysts during that period. The rise to glory of technical analysis is frequently attributed to the remarkable rise of the dollar between 1981 and 1985 to its highest level ever. The relentless appreciation of the dollar during that time period was unexplainable in terms of market fundamentals, such as interest rates and growth rates. Frustration with fundamental explanations of the dollar behaviour (and the consequent trading losses) led many analysts and investment managers to resort to technical analysis, a tendency that has created the status quo where technical analysis is taken seriously, even by anti-technical hardliners. The Frankel-Froot model was used by Vigfusson (1997), whereas Kirman (1991) presented an extension of the model. Levin (1997) developed a model involving the interaction between the expectations of chartists and fundamentalists.

By using a modified version of the Frankel-Froot model, Moosa and Korczak (2000) presented evidence indicating that (i) the exchange rate is determined by both technicians and fundamentalists, and (ii) fundamentalists play a bigger role in this respect. The second finding is justified on the grounds of using low-frequency data, which implies a long investment horizon. Moosa and Al-Loughani (2003) found some evidence indicating that the role of technicians is slightly more important than that of the fundamentalists. Variable addition tests revealed that the addition of the technicians' activity is more important than the addition of the fundamentalists' activity even though the coefficients on the variables representing the activities of fundamentalists and technicians turned out to be equal. Guest (2004) tested the same model using Australian spot and futures stock prices, producing evidence for the hypothesis that both fundamentalists and technicians have roles to play in price determination. Al-Muraikhi (2005) found similar results for the emerging stock and foreign exchange markets of Kuwait.

Survey evidence on the role played by fundamentalists and technicians is provided by a number of studies conducted on various markets. Harvey (1993, p.680) presents an interesting argument for survey evidence as an alternative to econometric modelling, stating that "more can be learned about the mysteries of international finance through understanding the propensities and proclivities of the traders than can be gleaned from a hundred multivariate regressions". Allen and Taylor (1989, 1990) and Taylor and Allen (1992) surveyed more than 400 foreign exchange dealers in London, with 60 per cent saying that charts are at least as important as fundamental analysis. Cheung et al. (2004) conducted a U.K.-based survey to find that technical-based trading was the preferred trading model. A subsequent survey by Oberlechner (2001) incorporated traders on all hierarchy levels in European foreign exchange markets, finding strong support for the use of technical analysis. Menkhoff (1997) and Lui and Mole (1998) obtained similar results from surveys conducted in the German and Hong Kong foreign exchange markets, respectively.

Evidence on the role played by fundamentalists and technicians is also provided by studies comparing the profitability of fundamental and technical trading rules, as well as studies stipulating heterogeneity in financial markets 
(see Moosa, 2003, pp. 236-240). The general conclusion of these studies is that both fundamentalists and technicians play a role in financial markets and that financial market participants are heterogenous with respect to the trading strategies they use. Pilbeam (1995a, 1995b) based his study of the profitability of foreign exchange trading on the notion of trader heterogeneity. In Pilbeam (1995b) traders are supposed to follow three different exchange rate determination models (the flexible-price monetary model, the sticky-price monetary model and the sticky-price portfolio balance model) in conjunction with six expectation formation mechanisms (static, extrapolative, adaptive, regressive, rational and heterogenous). In Pilbeam (1995a), traders are classified into chartists, fundamentalists and simpletons. The same idea forms the basis of the Post-Keynesian theory of exchange rate determination (see for example, Harvey, 1993).

Moosa (2002) presents a simple theoretical model that is based on the micro foundations of exchange rate determination to illustrate the relation between the heterogeneity of traders and volatility. The model is founded on the idea that observed exchange rate volatility can only result from erratic shifts in the market's excess demand function that is made up of the excess demand functions of heterogenous traders. The heterogeneity of traders means that they have different sentiments and different expectations at any point in time. Hence, they are likely to react differently to new developments: some want to buy (thus raising excess demand) and some want to sell (thus reducing excess demand). The net effect of their actions is to shift the aggregate excess demand function by a certain amount in a certain direction. In describing the model, Moosa assumes the presence of four kinds of traders: technicians using filter rules, technicians using moving average rules, fundamentalists using rules, and fundamentalists using discretion. This model was tested by Moosa and Shamsuddin (2003) who found that financial price formation results from the interaction of traders using a wide variety of technical and fundamental models.

The conclusion that can be safely derived from the preceding examination of the literature is that ample survey and econometric evidence show that both fundamentalists and technicians have roles to play in financial price determination. The evidence also indicates that the "balance of power" may tip in favour of one group of traders under certain circumstances. For example, the role of technicians is more important in situations involving short investment horizons. The empirical work conducted in this paper is designed to find out if this general conclusion holds for the Chinese stock market, which is attracting a lot of attention (see, for example, Gao, 2002; Fernald \& Rogers, 2002). This constitutes the motivation for writing this paper, as the findings will be useful for trading and policy purposes.

\section{Model Specification, Hypotheses and Estimation}

The specification of the models is derived from the following propositions. First, fundamentalists base their decisions (with respect to buying and selling stocks or 
financial assets in general) on the difference between the equilibrium price and the actual price. Hence, the current period's change in the price that is due to the operations of fundamentalists is given by

$$
\left(\Delta p_{t}\right)^{F}=\alpha\left(\bar{p}_{t-1}-p_{t-1}\right)
$$

where $p$ is the logarithm of the price, a bar denotes the equilibrium price, $F$ denotes fundamentalists and $\alpha$ is a positive parameter that reflects the speed of adjustment of the actual price to the deviation from the equilibrium price.

Technicians, on the other hand, base their decisions on previous changes in the price whether they use trading rules, follow quantitative technical indicators or simply observe charts. While this kind of behaviour can be represented by a number of specifications, our initial choice falls on a geometrically-declining distributed lag representation as proposed by Moosa and Korczak (2000). This specification is related to the use of an exponential moving average rule, which is a technical trading rule (buying and selling on signals indicated by the points of intersection of the price and its exponential moving average). Hence, the change in the price due to the activities of the technicians can be represented by the equation:

$$
\left(\Delta p_{t}\right)^{T}=\sum_{i=1}^{\infty} \beta^{i} \Delta p_{t-i}
$$

where $0<\beta<1$ and the superscript $T$ denotes technicians. If the activities of both fundamentalists and technicians contribute to price changes, the model can be written in a testable stochastic form as

$$
\Delta p_{t}=\gamma_{0}+\gamma_{1}\left(\bar{p}_{t-1}-p_{t-1}\right)+\gamma_{2} \sum_{i=1}^{\infty} \beta^{i} \Delta p_{t-i}+\varepsilon_{t}
$$

such that $\gamma_{1}>0$ and $\gamma_{2}>0$. If $\gamma_{1}>\gamma_{2}$, we may safely conclude that fundamentalists play a more significant role in price determination, and vice versa. The model represented by equation (3) will be called Model I.

The use of a geometrically-declining distributed lag to represent the reaction function of the technicians implies that technicians, who base their decisions on the past behaviour of prices, assign more significant weight to recent observations. This, however, may not be the case, as it could be that technicians look at a finite history of prices and assign similar weights to recent and less recent observations (hence the difference between an exponential and simple moving average rules). Allowing for the possibility of a different reaction function of technicians may be useful as a robustness check. Hence, the price change due to the activities of technicians may be represented by the equation

$$
\left(\Delta p_{t}\right)^{T}=\frac{1}{m} \sum_{i=1}^{m} p_{t-i}-\frac{1}{n} \sum_{i=1}^{n} p_{t-i}
$$


such that $m<n$. Equation (4) resembles the process used to generate buy and sell signals on the basis of moving average cross-over, as the first term on the right hand side of the equation represents the short moving average whereas the second term represents the long moving average. Simply stated, equation (4) represents another way of looking at the past behaviour of prices, which is what technicians do. In this case, the model becomes

$$
\Delta p_{t}=\gamma_{0}+\gamma_{1}\left(\bar{p}_{t-1}-p_{t-1}\right)+\gamma_{2}\left[\frac{1}{m} \sum_{i=1}^{m} p_{t-i}-\frac{1}{n} \sum_{i=1}^{n} p_{t-i}\right]+\varepsilon_{t}
$$

such that $\gamma 1>0$ and $\gamma 2>0$. Equation (5) will be called Model II.

Another modification to the model can be introduced by allowing an explicit role for the government in the stock price determination process, which may be necessary because the Chinese government has been keeping an open eye on trading to ensure a well-functioning market, and has power to intervene. However, any attempt to allow for the role played by the government in the stock market will be hampered by at least two problems. The first is that the Chinese government does not have an explicit objective with respect to the behaviour of stock prices. The second is that, even if such an objective exists, it is not easy to incorporate in the model. It is, however, plausible to assume that an objective of the Chinese government is to reduce market volatility, to maintain a smooth time path for stock prices. If this is the case, the role of government intervention can be modelled by borrowing an idea suggested by Hodrick and Prescott (1997) to construct the HP filter. They proposed, as a measure of the smoothness of the time path (trend) of a variable, the sum of squares of its second difference. As a modification of this idea, we suggest the use of a geometrically-declining distributed lag of the squares of the second difference of stock prices, which gives

$$
\left(\Delta p_{t}\right)^{g}=\sum_{i=1}^{\infty} \phi^{i}\left(\Delta^{2} p_{t-i}\right)^{2}
$$

where $\left(\Delta p_{t}\right)^{g}$ is the change in price due to government intervention. In this case the model is written as

$$
\Delta p_{t}=\gamma_{0}+\gamma_{1}\left(\bar{p}_{t-1}-p_{t-1}\right)+\gamma_{2} \sum_{i=1}^{\infty} \beta^{i} \Delta p_{t-i}+\gamma_{3} \sum_{i=1}^{\infty} \phi^{i}\left(\Delta^{2} p_{t-i}\right)^{2}+\varepsilon_{t}
$$

where $\gamma_{3}<0$. Equation (7) will be called Model III.

The models represented by equations (3), (5) and (7) are estimated by OLS, which is a valid procedure since the underlying variables are stationary. The unobserved equilibrium price, $\bar{p}$, is estimated by applying the Hodrick-Prescott (1997) filter to $p$. This is a detrending technique that is used to decompose an observed time series into trend and cycle. Formally, the HP filter is used to 
estimate the trend path $\left\{p_{t}^{*}, t=1,2, \cdots, n\right\}$ of the time series, $\left\{p_{t}, t=1,2, \cdots, n\right\}$ subject to the constraint that the sum of the squared second differences of the time series is not too large. ${ }^{1}$ The trend is calculated from the observed time series by solving the optimisation problem

$$
\min _{p_{1}^{*}, p_{2}^{*}, \cdots p_{n}^{*}}\left\{\sum_{t=1}^{n}\left(p_{t}-p_{t}^{*}\right)^{2}+\lambda \sum_{t=2}^{n-1}\left(\Delta^{2} p_{t+1}^{*}\right)^{2}\right\}
$$

where the smoothing parameter, $\lambda$, is typically determined by the frequency of the observations. In essence, the equilibrium price is taken to be the fitted HP trend. Although the HP filter is not the only means whereby a proxy for the equilibrium price can be obtained, it is assumed here that the long-run trend of the price reflects the behaviour of the fundamental variables determining its equilibrium price. By using a specific fundamental model to estimate the equilibrium value, we run the risk of not capturing all of the fundamental variables, and hence the risk of misrepresenting the equilibrium price.

For estimating the geometrically-declining distributed lags, the choice of the values of the parameters $\beta$ and $\phi$ is arbitrary, but a value of 0.8 seems reasonable because it means that the technicians assign more weight to more recent observations on $\Delta p_{t-i}$ and $\left(\Delta^{2} p_{t-i}\right)^{2}$. As a robustness check, other values of the parameter were tried but made no qualitative difference to the results. Similar procedures are used for the determination of the values of $m$ and $n$ in equation $(5) .^{2}$

Following the estimation of the models, the importance of fundamentalists relative to technicians is determined by testing the null hypothesis

$$
H_{0}: \gamma_{1}=\gamma_{2}
$$

which amounts to a Wald test where the test statistic has a $\chi^{2}(1)$ distribution, since there is only one restriction on the values of the estimated coefficients. If $\mathrm{H}_{0}$ is rejected such that $\gamma_{1}>\gamma_{2}$, then the role of fundamentalists is more important than the role of technicians, and vice versa.

Also used are variable deletion tests. To find out if fundamentalists play a role in stock price determination, the coefficient restriction $\gamma_{1}=0$ is imposed. A significant test statistic in this case implies that the restriction is invalid, meaning that fundamentalists play a role in price determination (and vice versa). On the basis of the residual sum of squares of the unrestricted models (3, 5 and 7) and

1 This is the idea of representing smoothness by the sum of the squared second differences of the underlying variable. This representation was used earlier to specify a proxy for the role of government intervention in the stock market.

2 Theory does not provide any guidance on the values of $\beta, \phi, m$ and $n$. Intuition and robustness checks provide the key to the selection of appropriate values of these parameters. 
the restricted models (resulting from the imposition of the restriction $\gamma_{1}=0$ ), two test statistics are calculated: a Lagrange multiplier (LM) and a likelihood ratio (LR) test statistics. Both of these statistics follow a $\chi^{2}(1)$ distribution, since only one coefficient restriction is imposed. Likewise, the restriction $\gamma_{2}=0$ is imposed to find out if technicians play a role in price determination.

Non-nested model selection tests are used to find out if either technicians or fundamentalists can on their own determine stock prices. Consider the following two models, M1 and M2:

$$
\begin{gathered}
\text { M1: } \Delta p_{t}=X \delta_{1}+\xi_{1} \\
\text { M2: } \Delta p_{t}=Z \delta_{2}+\xi_{2}
\end{gathered}
$$

where $X$ is an observation matrix on the variable representing the role of fundamentalists (plus the role of the government if necessary), $Z$ is an observation matrix on the variable representing the role of technicians (plus the role of the government if necessary), $\delta_{1}$ and $\delta_{2}$ are unknown regression coefficient vectors, and $\xi_{1}$ and $\xi_{2}$ are disturbance vectors. In the particular case under investigation here, M1 and M2 are related to the models represented by equations (3), (5) and (7), as the former can be obtained by imposing some restrictions on the latter. The M1 and M2 corresponding to equation (3) are given respectively by

$$
\begin{aligned}
& \text { M1: } \Delta p_{t}=\gamma_{0}+\gamma_{1}\left(\bar{p}_{t-1}-p_{t-1}\right)+\varepsilon_{t} \\
& \text { M2: } \Delta p_{t}=\gamma_{0}+\gamma_{2} \sum_{i=1}^{\infty} \beta^{i} \Delta p_{t-i}+\varepsilon_{t}
\end{aligned}
$$

which tell us that stock prices are determined exclusively by the activities of fundamentalists (M1 as represented by equation 12) or exclusively by the activities of the technicians (M2 as represented by equation 13). The M1 model corresponding to equation (5) is the same as equation (12) but M2 becomes

$$
\text { M2: } \Delta p_{t}=\gamma_{0}+\gamma_{2}\left[\frac{1}{m} \sum_{i=1}^{m} p_{t-i}-\frac{1}{n} \sum_{i=1}^{n} p_{t-i}\right]+\varepsilon_{t}
$$

Likewise, the M1 and M2 corresponding to equation (7) are given respectively by

$$
\text { M1: } \Delta p_{t}=\gamma_{0}+\gamma_{1}\left(\bar{p}_{t-1}-p_{t-1}\right)+\gamma_{3} \sum_{i=1}^{\infty} \phi^{i}\left(\Delta^{2} p_{t-i}\right)^{2}+\varepsilon_{t}
$$




$$
\text { M2: } \Delta p_{t}=\gamma_{0}+\gamma_{2} \sum_{i=1}^{\infty} \beta^{i} \Delta p_{t-i}+\gamma_{3} \sum_{i=1}^{\infty} \phi^{i}\left(\Delta^{2} p_{t-i}\right)^{2}+\varepsilon_{t}
$$

The models M1 and M2 are said to be non-nested if the regressors of either of them cannot be expressed as an exact linear combination of the regressors of the other. Obviously, M1 and M2 as represented by equations (12)-(16) are nonnested because either the explanatory variables are different (as in 12 and 13) or because there is a common explanatory variable but the other one appears in one equation only (as in 15 and 16).

Six model selection tests are used: $N$ is the Cox test derived in Pesaran (1974); NT is the adjusted Cox test derived in Godfrey and Pesaran (1983); $W$ is the Wald-type test proposed by Godfrey and Pesaran (1983); $J$ is the Davidson and MacKinnon (1981) test; $J A$ is the Fisher-McAleer (1981) test; and $E N$ is the encompassing test proposed, inter alia, by Mizon and Richard (1986). All of the test statistics have $t$ distribution, except for the encompassing test that has $\mathrm{F}$ distribution. The tests are run both ways by testing M1 versus M2 and M2 versus M1. When M1 is tested versus M2, the null hypothesis is that M1 is a better model (in terms of specification) than M2. A significant test statistic indicates that M1 is not a better model than M2. When M2 is tested against M1, the null is that M2 is a better model than M1. A significant test statistic indicates that M2 is not a better model than M1. If we obtain significant test statistics both ways, this means that the two models are misspecified (that is, neither fundamentalists nor technicians can determine prices on their own). If we get insignificant test statistics by testing M1 versus M2 and significant statistics by testing M2 versus $\mathrm{M} 1$, this means that $\mathrm{M} 1$ is preferred to $\mathrm{M} 2$ (that is, fundamentalists alone determine stock prices). The econometrics of non-nested model selection tests can be found in Pesaran and Pesaran (1997).

\section{Empirical Results}

The empirical work conducted in this paper is based on monthly and daily data on the stock prices of one hundred listed companies, obtained from the Taiwan Economic Journal database. The appendix displays the names of the companies, the sectors they belong to, their markets values (in RMB billion) and the sample periods. The listing of market values is useful to find out if size matters, in the sense that the results are (or are not) affected by the market value of the company used to carry out the test. ${ }^{3}$ The stocks were selected randomly from the full list of

\footnotetext{
3 There is no obvious theoretical reason to believe that fundamentalists play a more important role than technicians in the determination of the stock prices of large companies than those of small companies or vice versa. But it could be that large companies are better audited and that they publish more detailed financial reports than small companies, which makes them better suited to fundamental analysis than small companies. In any case, this is an issue that is worth exploring.
} 
the stocks traded on the Shanghai Stock Exchange. To ensure random selection, a random number generator was used to pick the companies according to their Shanghai Stock Exchange codes.

With one hundred companies, two frequencies and three models, the amount of results is too big to report in a tabular form. What we have decided to do is to report the results primarily in a graphical form, while reporting a sample of the results of estimating Model I in a tabular form for eight selected companies, chosen as representatives of eight different percentiles of market values, including the smallest and largest companies. ${ }^{4}$ The selected companies for which the results are reported are 1, 17, 22, 31, 40, 5572 and 85. The details of these companies can be found in the Appendix.

The results of estimating Model I, as represented equation (3), for the eight selected companies are reported in Table 1, including the estimated coefficients and their $\mathrm{t}$ statistics (in parentheses), as well as the coefficient of determination $\left(R^{2}\right)$ and the diagnostics for serial correlation $(S C)$, functional form $(F F)$ and heteroscedasticity $(H S)$, all of which have $\chi^{2}$ distribution (with one degree of freedom for daily data and the same for monthly data, except for the serial correlation test statistic that has 12 degrees of freedom for monthly data). The estimated equations pass the diagnostic tests, producing significantly positive coefficients in all cases. The null hypothesis $\mathrm{H}_{0}: \gamma_{1}=\gamma_{2}$ is rejected across the board, which means that although both fundamentalists and technicians have roles to play, the latter play a more important role in terms of exerting more influence on the market price $\left(\gamma_{2}>\gamma_{1}\right.$ in all cases).

Table 2 reports the results of the variable deletion tests for the eight selected companies. In all cases, the LM and LR statistics are significant, which means that the null hypothesis is rejected, implying that both fundamentalists and technicians have roles to play. These results are supported by the results of the non-nested model selection tests, which are presented in Table 3. With few exceptions, the test statistics are significant (both ways), implying that both M1 and M2 are misspecified and that the correctly-specified model should include terms that represent the activities of fundamentalists and technicians. ${ }^{5}$

\footnotetext{
4 The full set of results, in a tabular form, encompassing 100 companies, two frequencies and three models is available from the authors upon request.

5 The J, JA and EN tests are consistent in rejecting M1 versus M2 and M2 versus M1. However, the N, NT and W tests show cases where M2 is not rejected versus M1 (31, 40 and 85), implying that the role of fundamentalists can be ignored. However, the bulk of the evidence indicates that the activities of both fundamentalists and technicians do matter.
} 


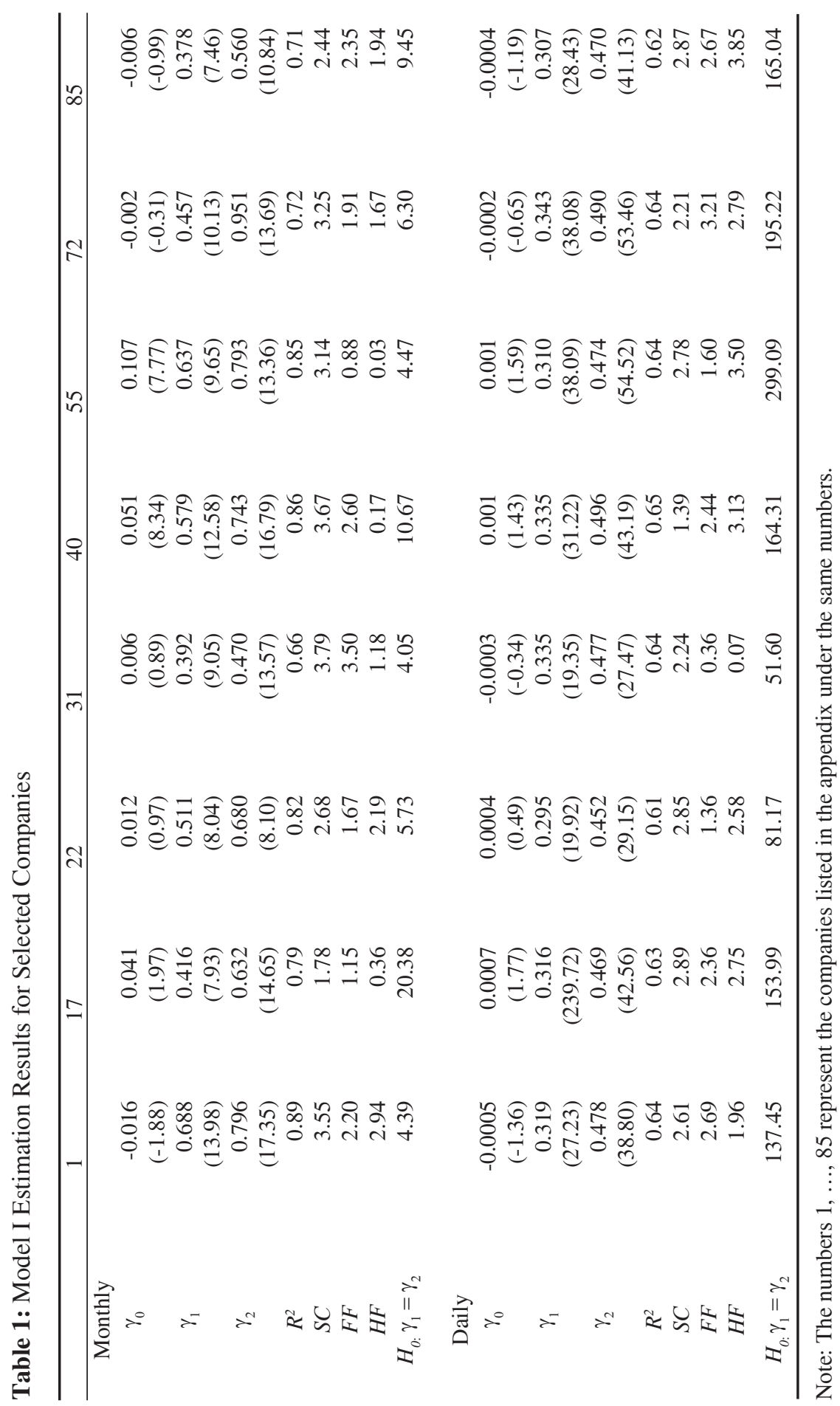



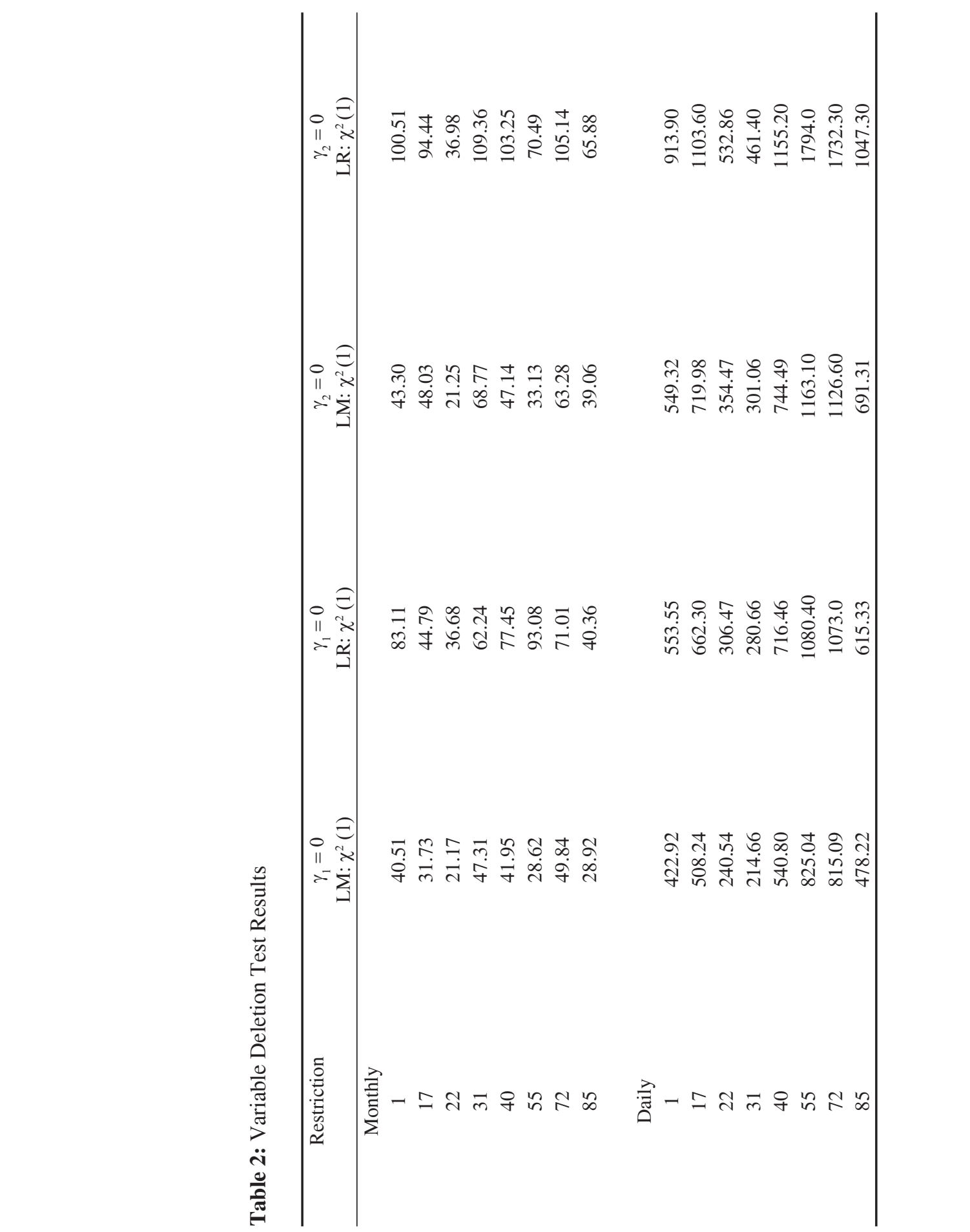


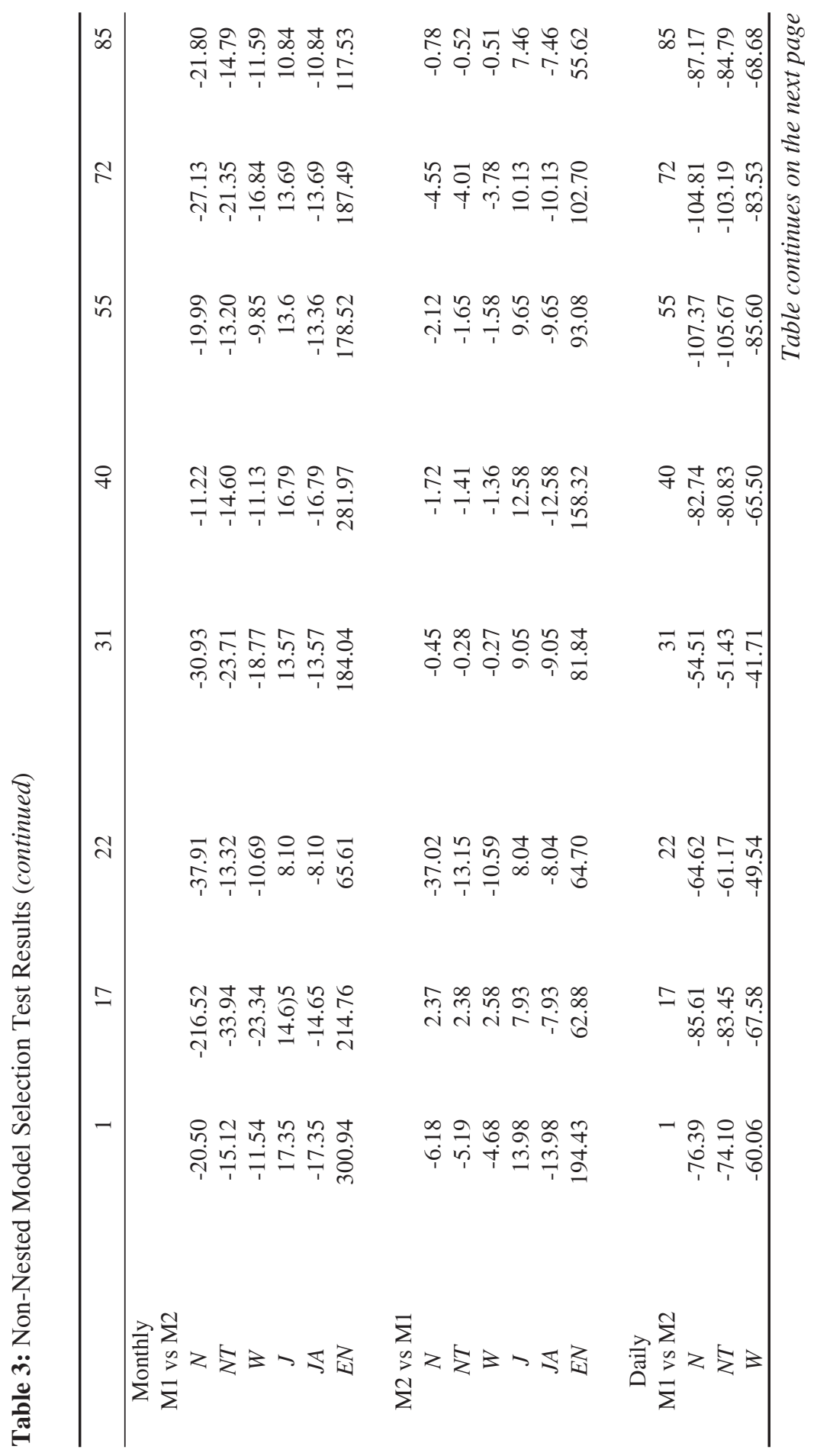



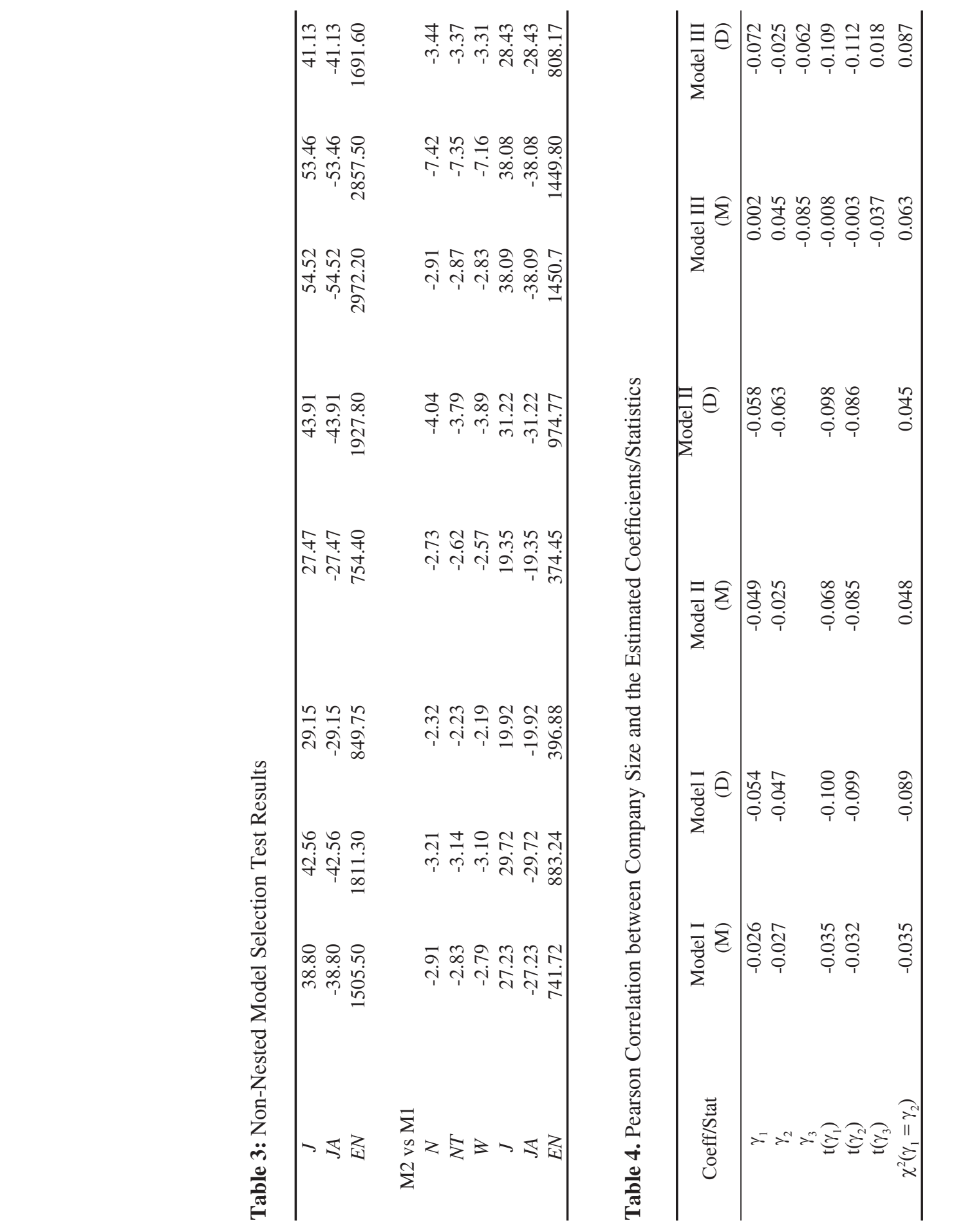
The full results are presented in a graphical form in Figures 1 to 6, two tables for models I, II and III, covering the monthly and daily frequencies. Figure 1 reports the results for model I using monthly data. It consists of three parts ( $a, b$ and c), respectively showing the estimated values of $\gamma_{1}$ and $\gamma_{2}$ (Figure 1(a)), their $\mathrm{t}$ statistics (Figure 1(b)) and the $\chi^{2}$ statistics for the null hypothesis $\gamma_{1}=\gamma_{2}$ (Figure 1(c)). To make the graphs easier to follow visually, the estimated values of the coefficients and the test statistics are sorted in an ascending order whenever necessary.

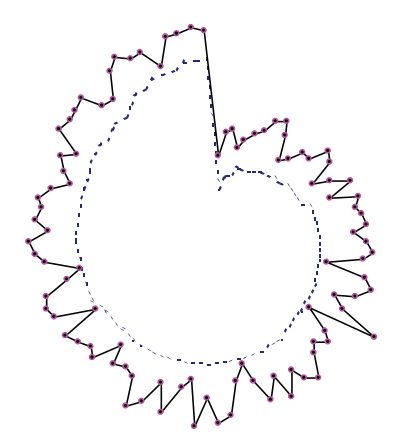

Fundamentalists —— Technicians

Figure 1: The Empirical Results (Model I, Monthly Data)

(a) A Radar Chart of the Estimated Coefficients on the Activities of Fundamentalists (Sorted) and Technicians

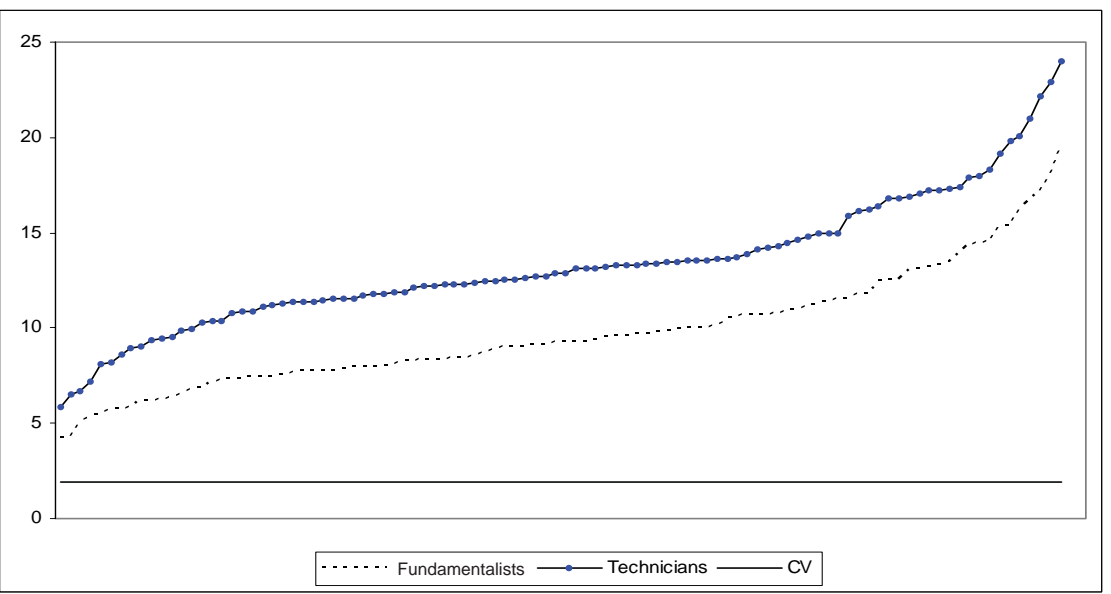

(b) The Sorted t Statistics of the Coefficients on the Activities of Fundamentalists and Technicians with the 5\% Critical Value 


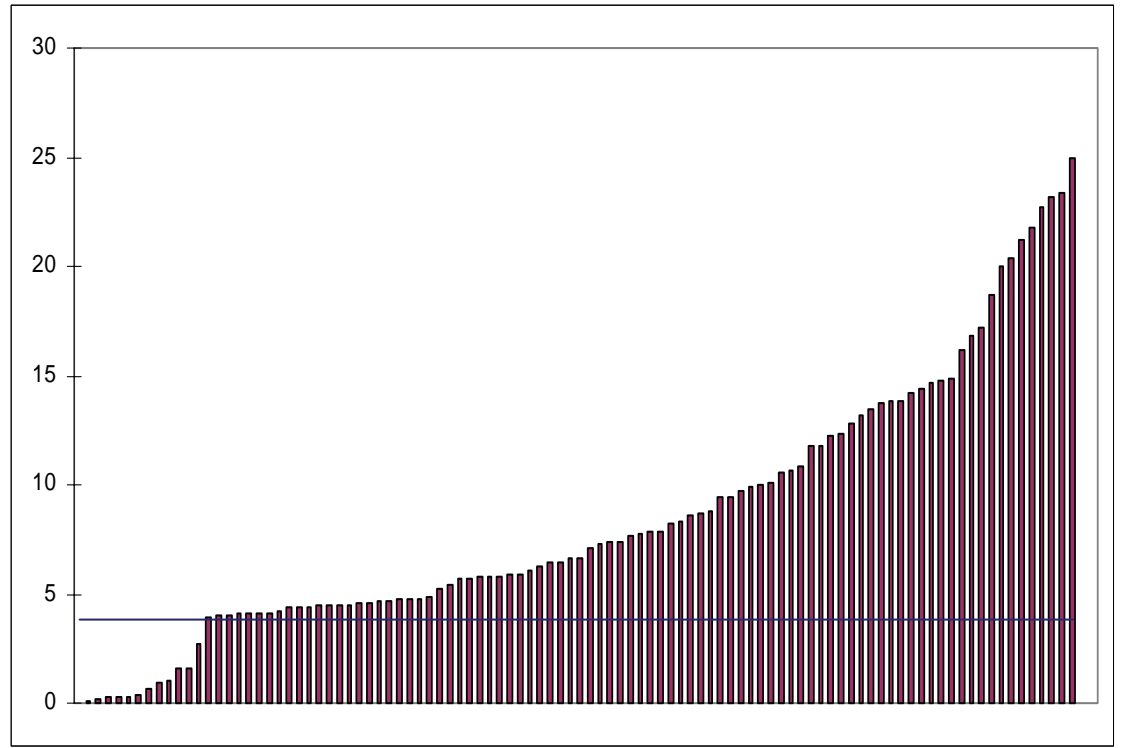

Figure 1:

(c) The Sorted Chi-Square Test Statistics for the Equality of the Coefficients with the $5 \%$ Critical Value

Figure 1(a) is a radar chart showing the sorted estimated values of $\gamma_{1}$ (fundamentalists) and the corresponding estimated values of $\gamma_{2}$ (technicians). The chart shows that $\gamma_{2}>\gamma_{1}$ in all of the 100 cases, as the two loops representing $\gamma_{1}$ and $\gamma_{2}$ do not intersect (the loop representing $\gamma_{1}$ is nested within the loop representing $\gamma_{2}$ ). Figure 1(b) shows the sorted t statistics of the estimated values of $\gamma_{1}$ (fundamentalists) and $\gamma_{2}$ (technicians), together with the approximate $5 \%$ critical value of the $\mathrm{t}$ statistic, represented by the horizontal line cutting the vertical axis at 1.96. Across the board, the t statistics are above the critical value, indicating the significance of $\gamma_{1}$ and $\gamma_{2}$. Figures 1(a) and 1(b) show unequivocally that while both fundamentalists and technicians play a role in stock price determination, technicians play a more important role, in the sense that their activities have a quantitatively more significant impact on stock prices. Figure 1(c) displays the sorted $\chi^{2}$ statistics for the null hypothesis $\gamma_{1}=\gamma_{2}$ as well as its $5 \%$ critical value, represented by the horizontal line cutting the vertical axis at 3.84. The $\chi^{2}$ statistics are insignificant in 12 cases out of 100 , implying that the bulk of the evidence indicates that both fundamentalists and technicians have roles to play in stock price determination. 

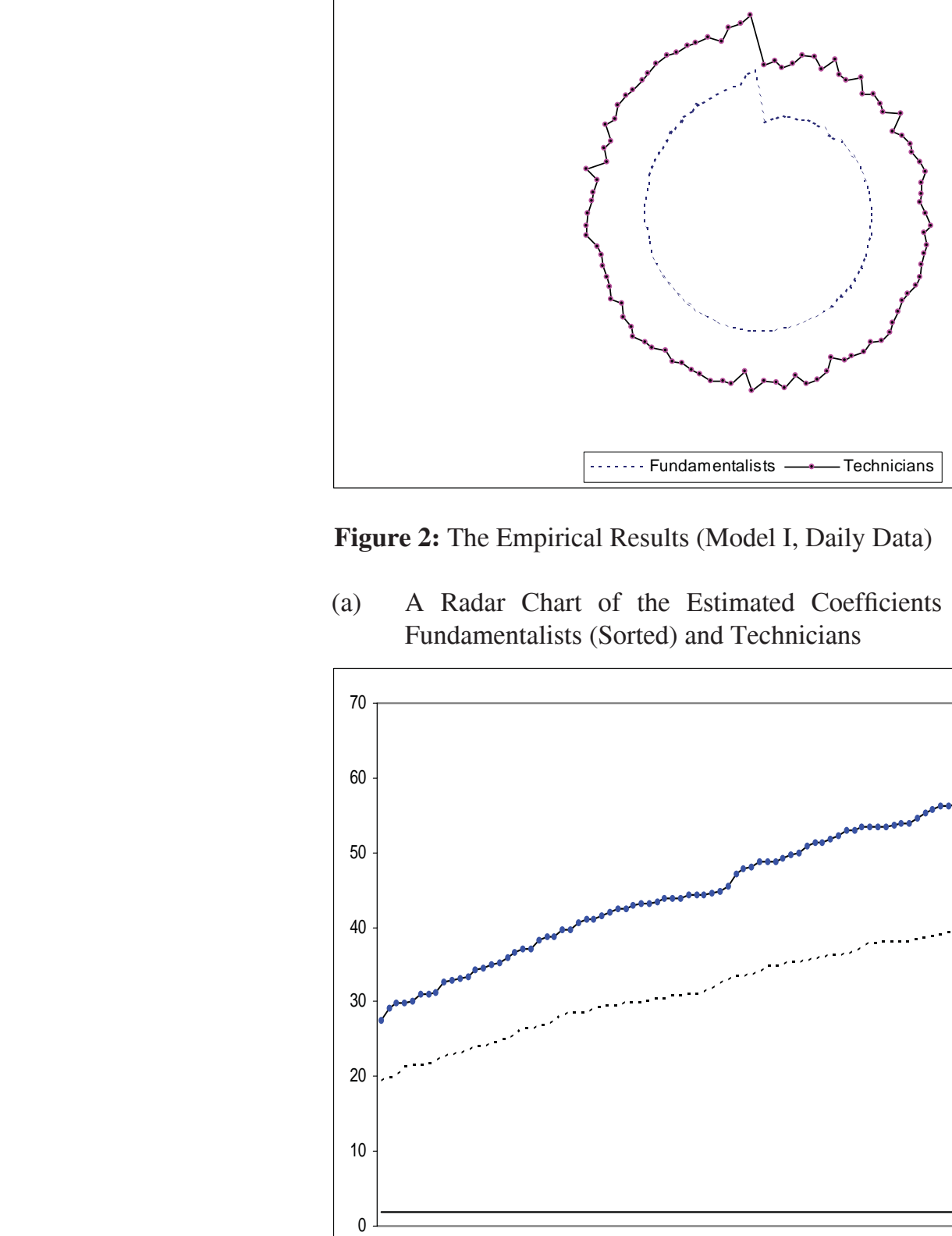

Figure 2: The Empirical Results (Model I, Daily Data)

(a) A Radar Chart of the Estimated Coefficients on the Activities of Fundamentalists (Sorted) and Technicians

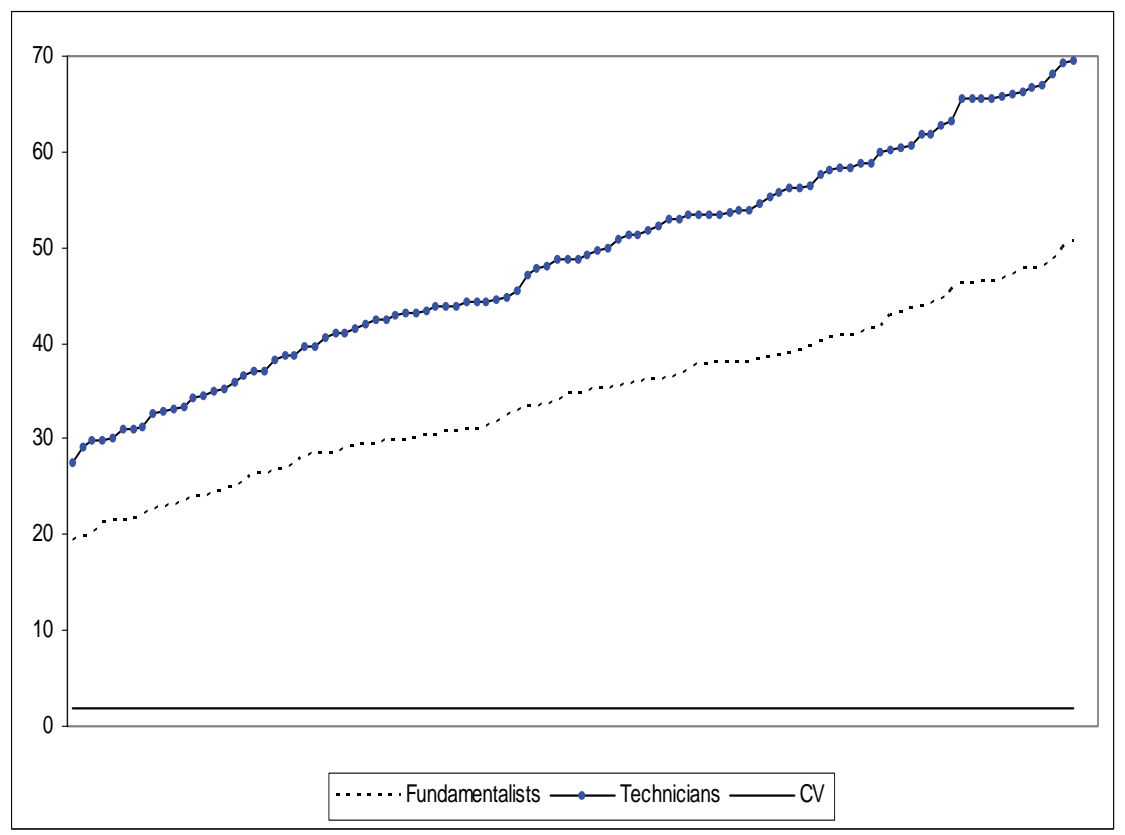

Figure 2: (Continued)

(b) The Sorted $\mathrm{t}$ Statistics of the Coefficients on the Activities of Fundamentalists and Technicians with the 5\% Critical Value 
Figure 2 is exactly like Figure 1, except that it shows the results of estimating Model I using daily data. The results are unanimous: both fundamentalists and technicians play a role in stock price determination, but technicians play a quantitatively more important role without any exception. Of a particular interest is Figure 3(c), which shows that the $\chi^{2}$ statistic for the null hypothesis $\gamma_{1}=\gamma_{2}$ is not insignificant in any of the 100 cases (compared with insignificant statistics in 12 cases when monthly data are used, as shown in Figure 1(c)). There is a simple explanation for this observation.

The results are more strongly in favour of a more significant role for the technicians when daily data are used, because it is not possible to observe fundamentals on a daily basis. Indeed, the available survey evidence on the role of technicians and fundamentalists in financial price determination indicates that the tendency to use technical analysis increases as the investment horizon becomes shorter.

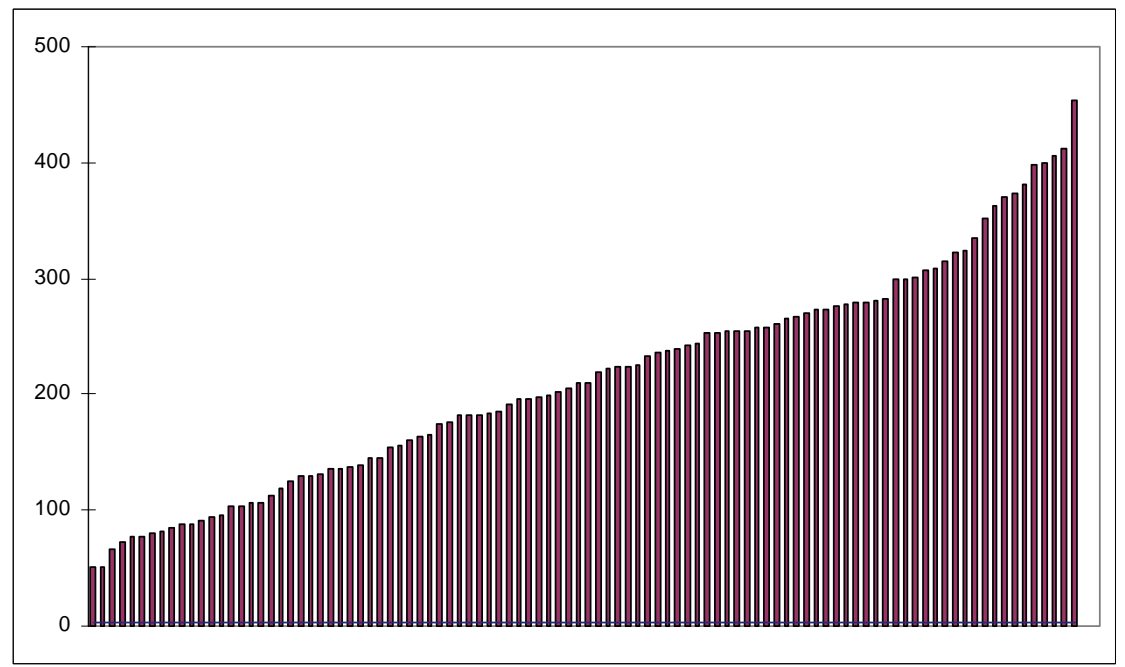

(c) The Sorted Chi-Square Test Statistics for the Equality of the Coefficients with the $5 \%$ Critical Value

Figure 3 and Figure 4 show exactly the same findings for Model II when monthly and daily data are used, respectively. 

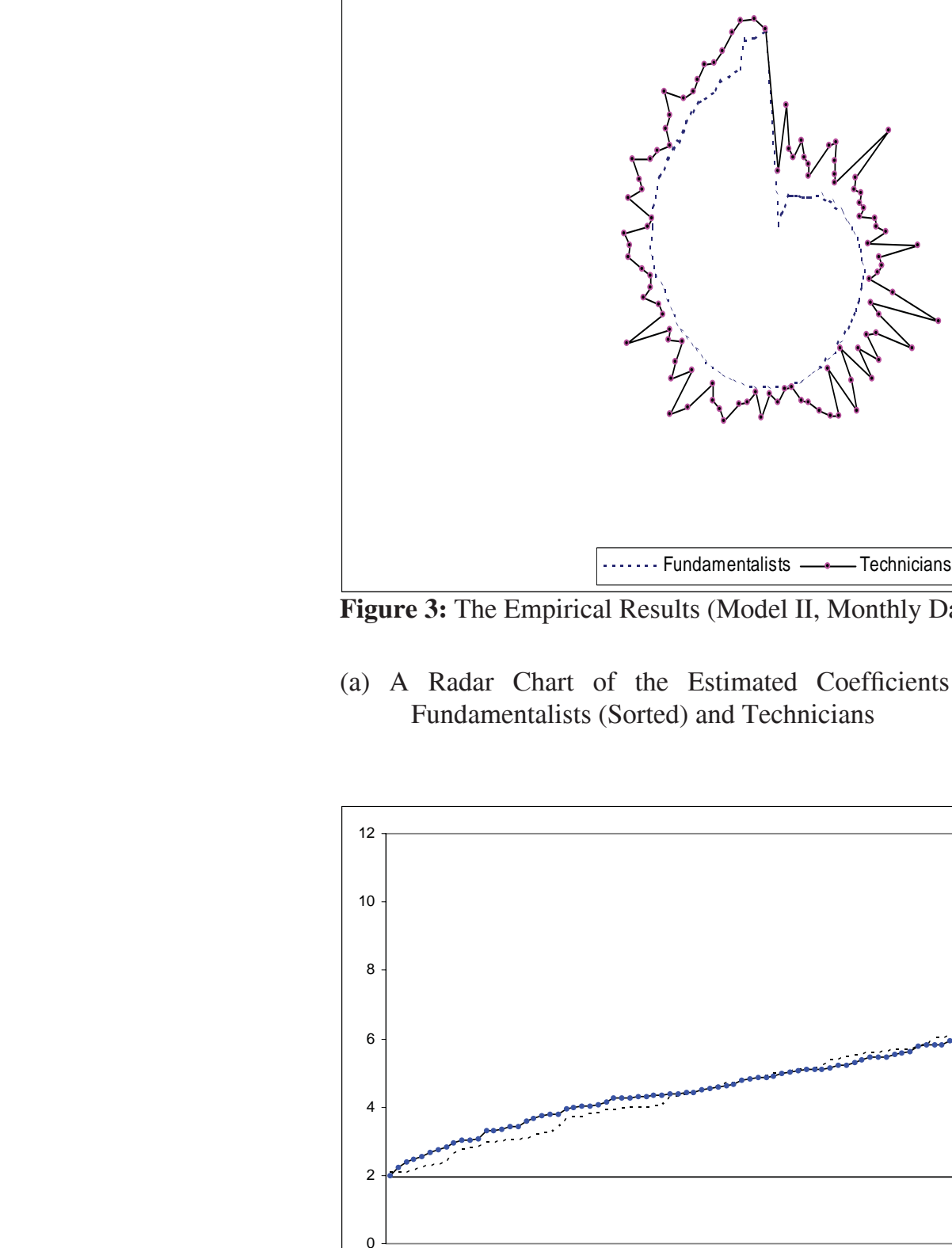

....... Fundamentalists —-Technicians

Figure 3: The Empirical Results (Model II, Monthly Data)

(a) A Radar Chart of the Estimated Coefficients on the Activities of Fundamentalists (Sorted) and Technicians

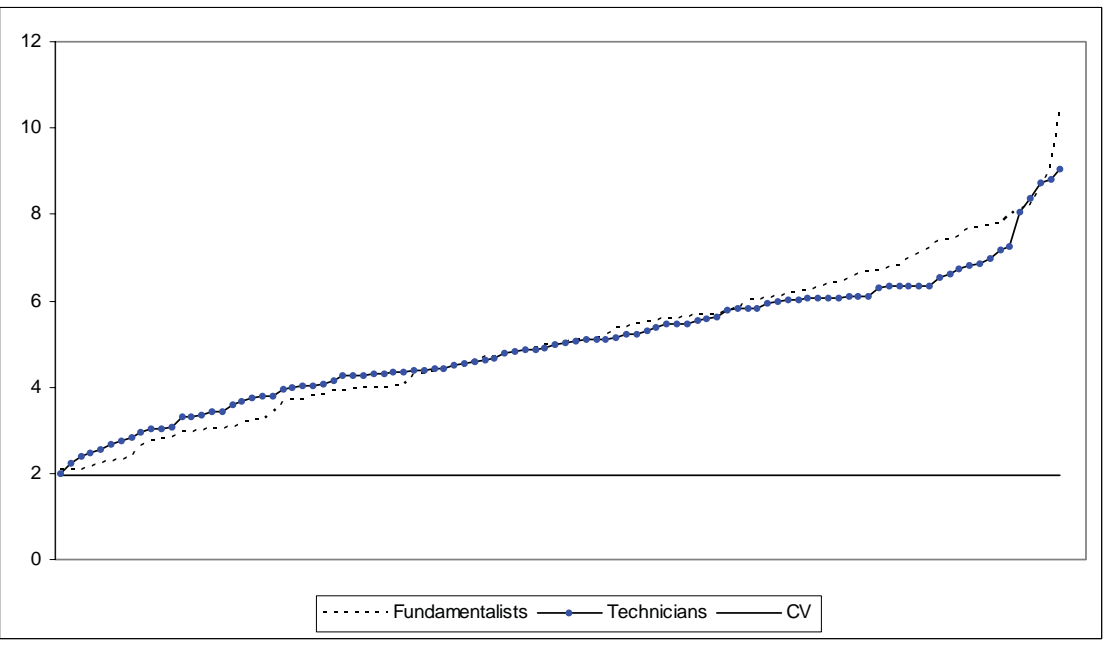

Figure 3: (Continued)

(b) The Sorted $t$ Statistics of the Coefficients on the Activities of Fundamentalists and Technicians with the 5\% Critical Value 


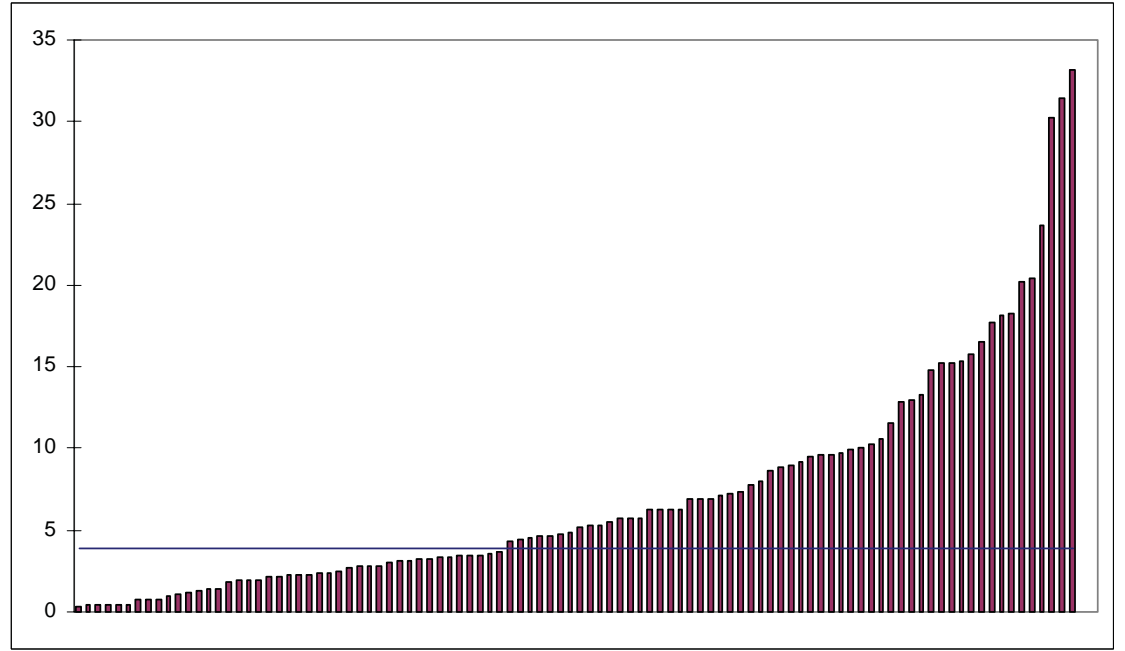

(c) The Sorted Chi-Square Test Statistics for the Equality of the Coefficients with the $5 \%$ Critical Value

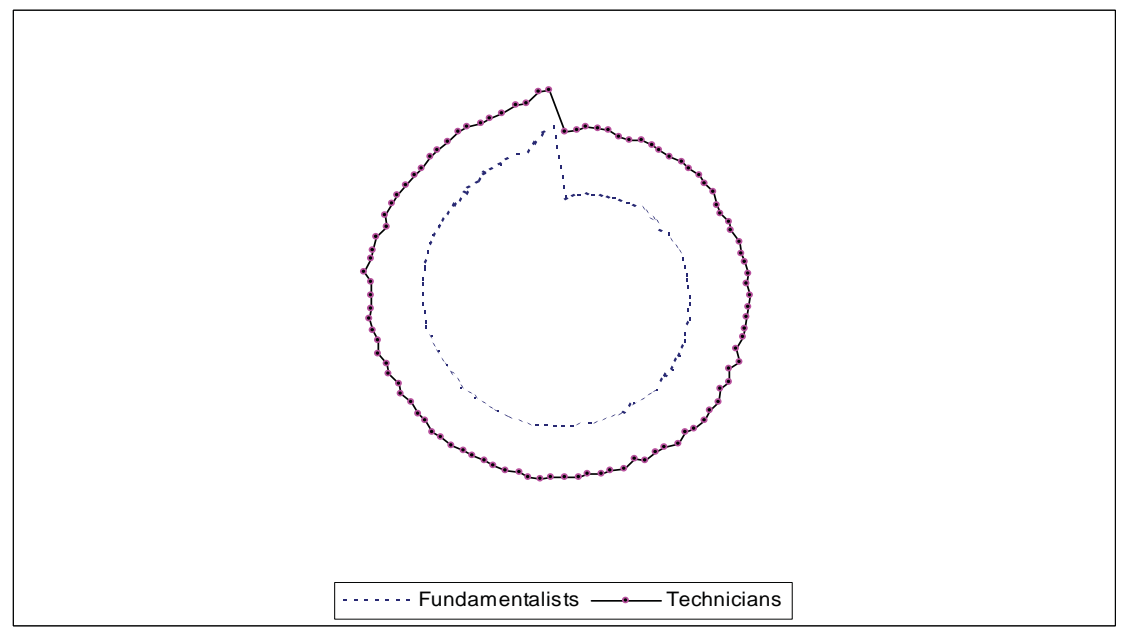

Figure 4: The Empirical Results (Model II, Daily Data)

(a) A Radar Chart of the Estimated Coefficients on the Activities of Fundamentalists (Sorted) and Technicians

The first point to observe is that changing the representation of the activities of technicians does not make any qualitative difference for the results, which consistently show $\gamma_{1}$ and $\gamma_{2}$ to be significantly positive and that $\gamma_{2}>\gamma_{1}$ in all cases. Like Figure 1(c), and unlike Figures 2(c) and 4(c), Figure 3(c) shows some insignificant $\chi^{2}$ statistics for the null hypothesis $\gamma_{1}=\gamma_{2}$, implying that 
when monthly data are used there is some indication (though not overwhelming) that technicians and fundamentalists play similarly significant roles in stock price determination. This finding is not apparent in Figure 4(c), which is based on daily data.

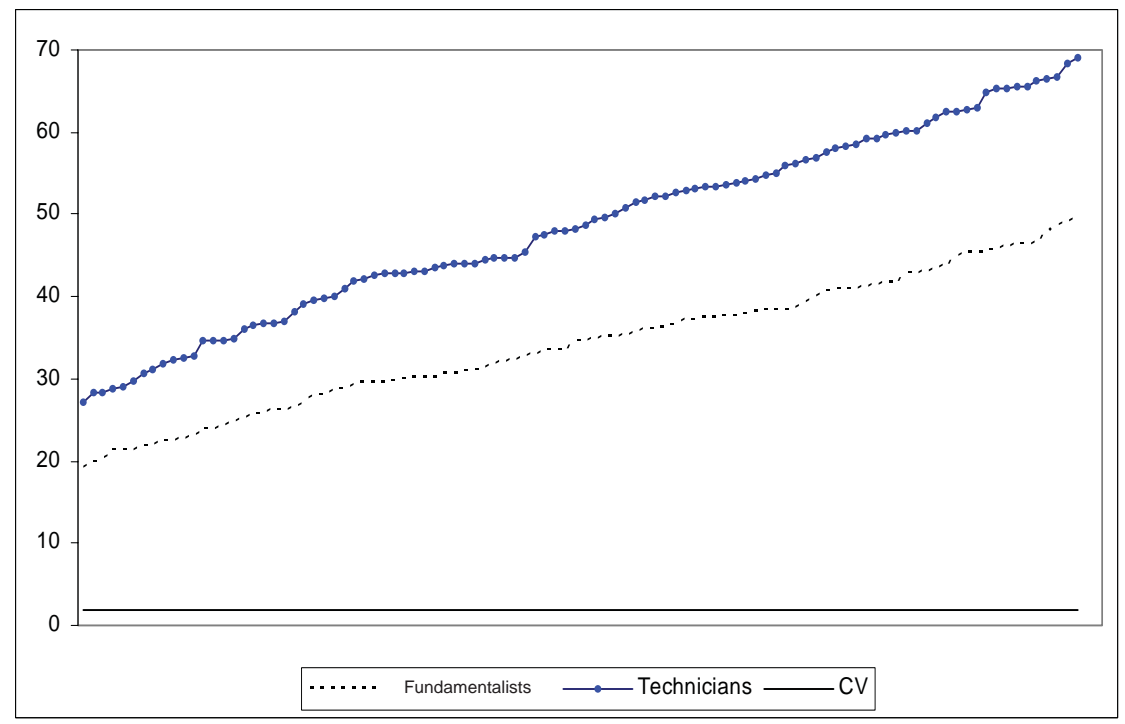

(b) The Sorted $t$ Statistics of the Coefficients on the Activities of Fundamentalists and Technicians with the 5\% Critical Value

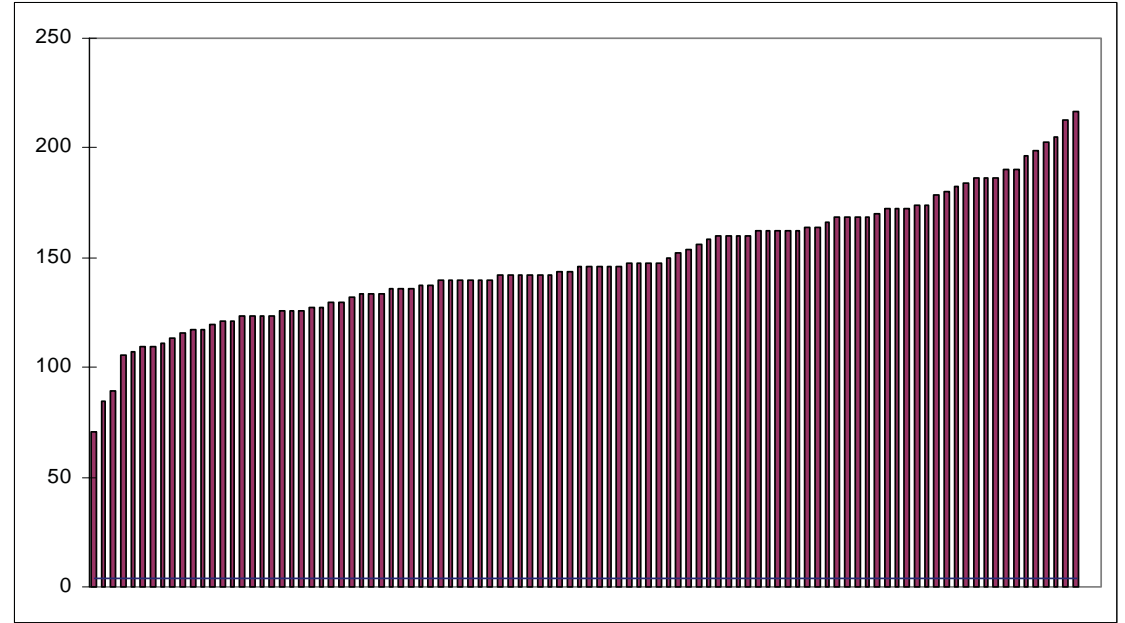

Figure 4: (Continued)

(c) The Sorted Chi-Square Test Statistics for the Equality of the Coefficients with the 5\% Critical Value 

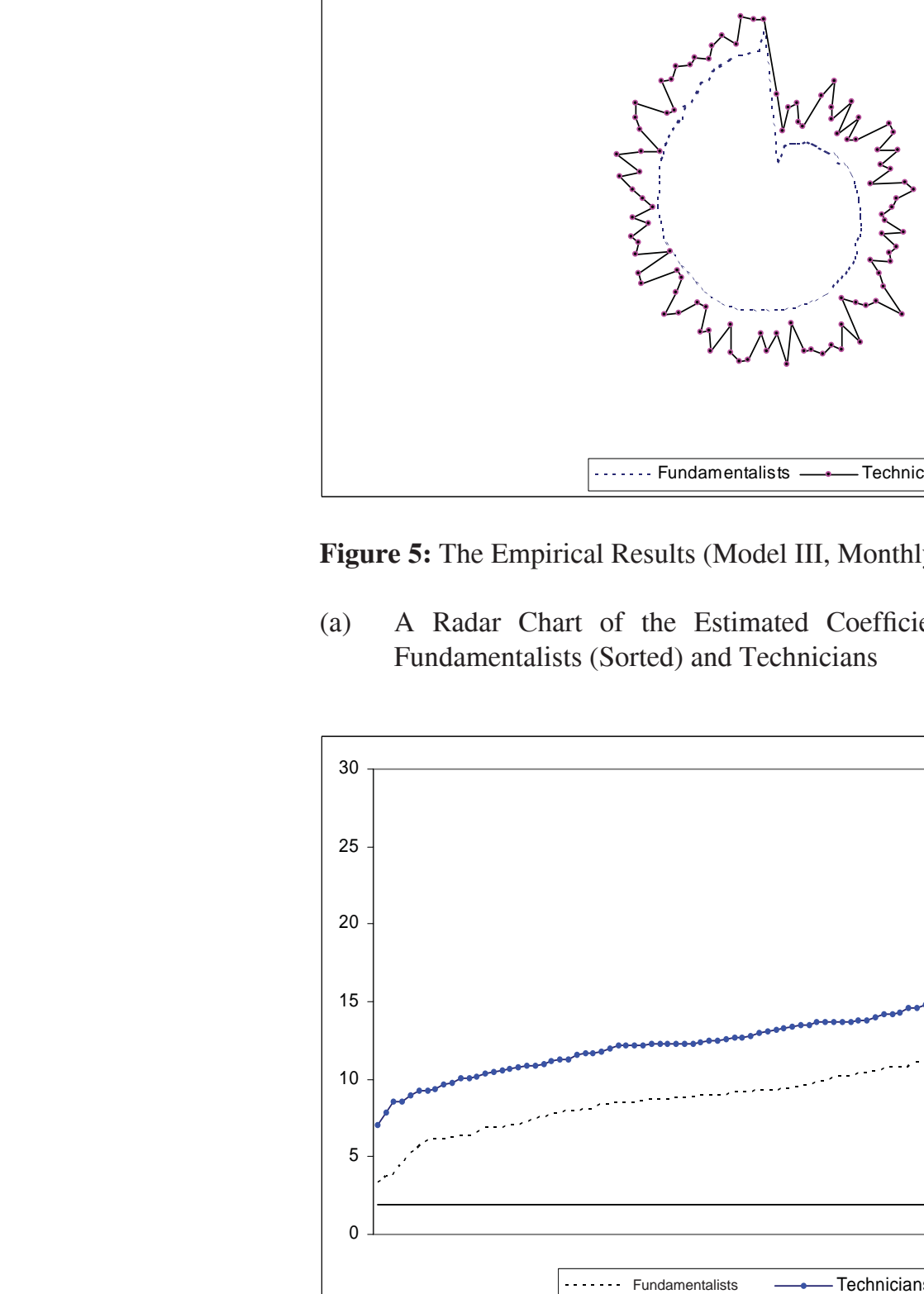

Figure 5: The Empirical Results (Model III, Monthly Data)

(a) A Radar Chart of the Estimated Coefficients on the Activities of Fundamentalists (Sorted) and Technicians

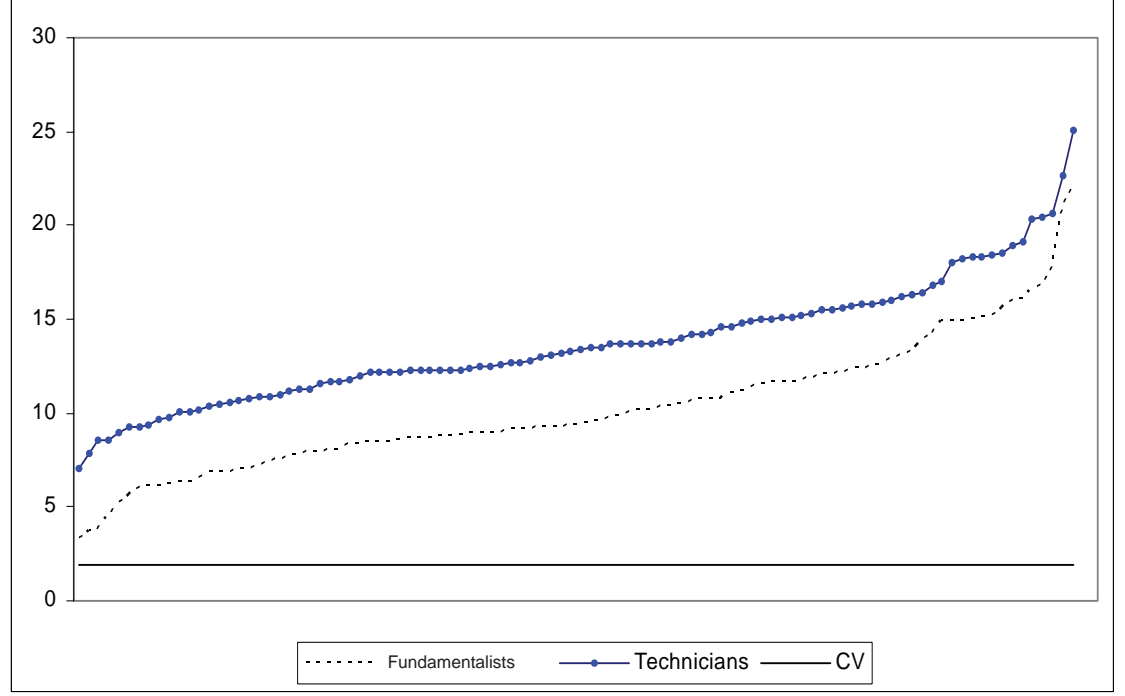

(b) The Sorted $t$ Statistics of the Coefficients on the Activities of Fundamentalists and Technicians with the 5\% Critical Value 
Figures 5 and 6 report the empirical results of estimating Model III using monthly and daily data, respectively. Exactly the same results hold, confirming the overall importance of technicians relative to fundamentalist. One additional advantage of Model III is that it allows for an explicit role for government intervention in the stock market. Referring to equation (7), if the objective of government intervention is to reduce the volatility of (and maintain a smooth time path for) stock prices, the government intervention variable should be negatively related to the dependent variable. This means that if government intervention is effective then $\gamma_{3}<0$. Figures 5(c) and 6(c) show the sorted $t$ statistics of $\gamma_{3}$, together with the positive and negative $5 \%$ critical values of the $t$ statistic (cutting the vertical axis at 1.96 and -1.96 , respectively). The results are supportive of the role of government intervention as $\gamma_{3}$ is significantly negative in just under half of the 100 cases. Not in one case does $\gamma_{3}$ turn out to be is significantly positive.

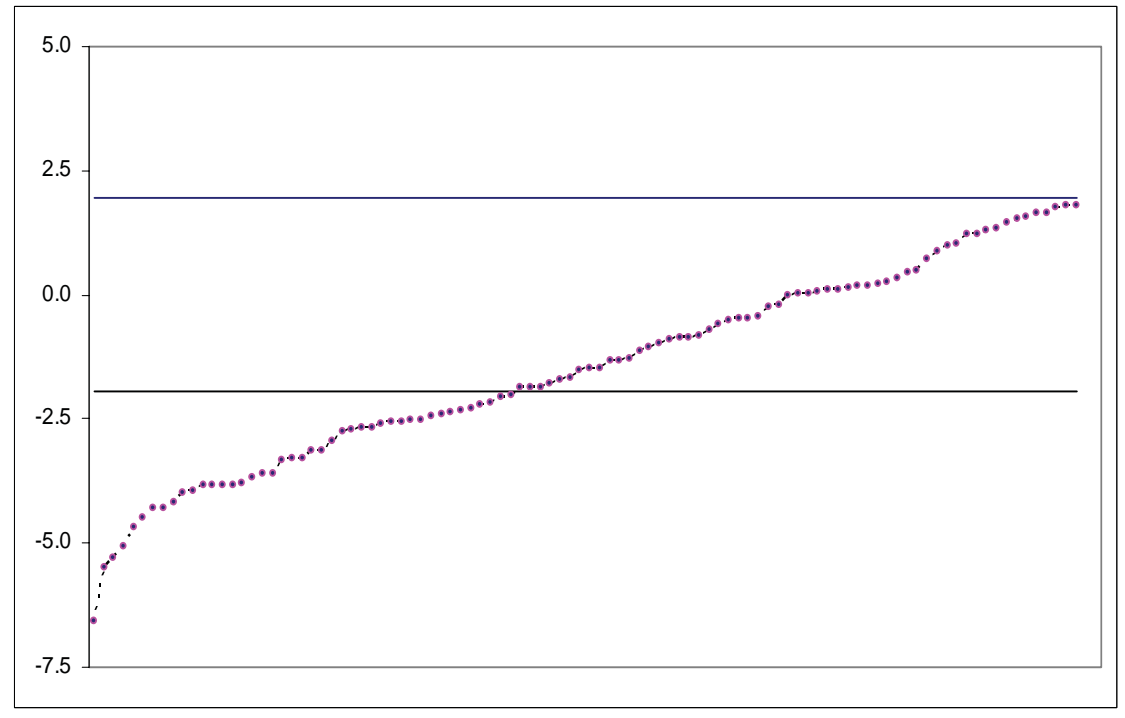

Figure 5: (Continued)

(c) The Sorted t Statistics of the Coefficient on the Government Intervention Variables with the Positive and Negative 5\% Critical Values 


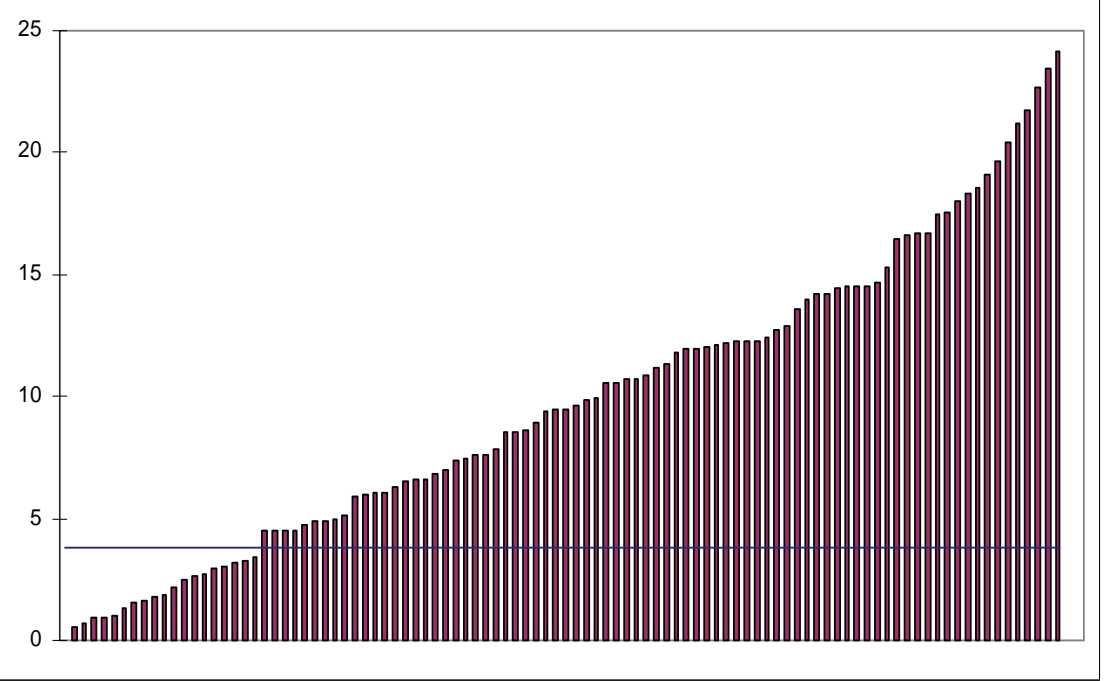

(d) The Sorted Chi-Square Test Statistics for the Equality of the Coefficients with the 5\% Critical Value

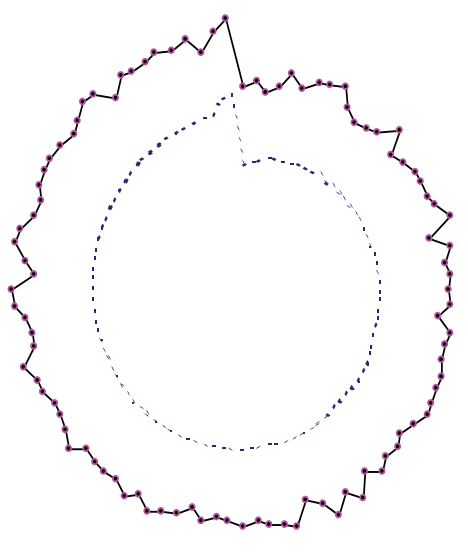

...... Fundamentalists $\longrightarrow$ - Technicians

Figure 6: The Empirical Results (Model III, Daily Data)

(a) A Radar Chart of the Estimated Coefficients on the Activities of Fundamentalists (Sorted) and Technicians 


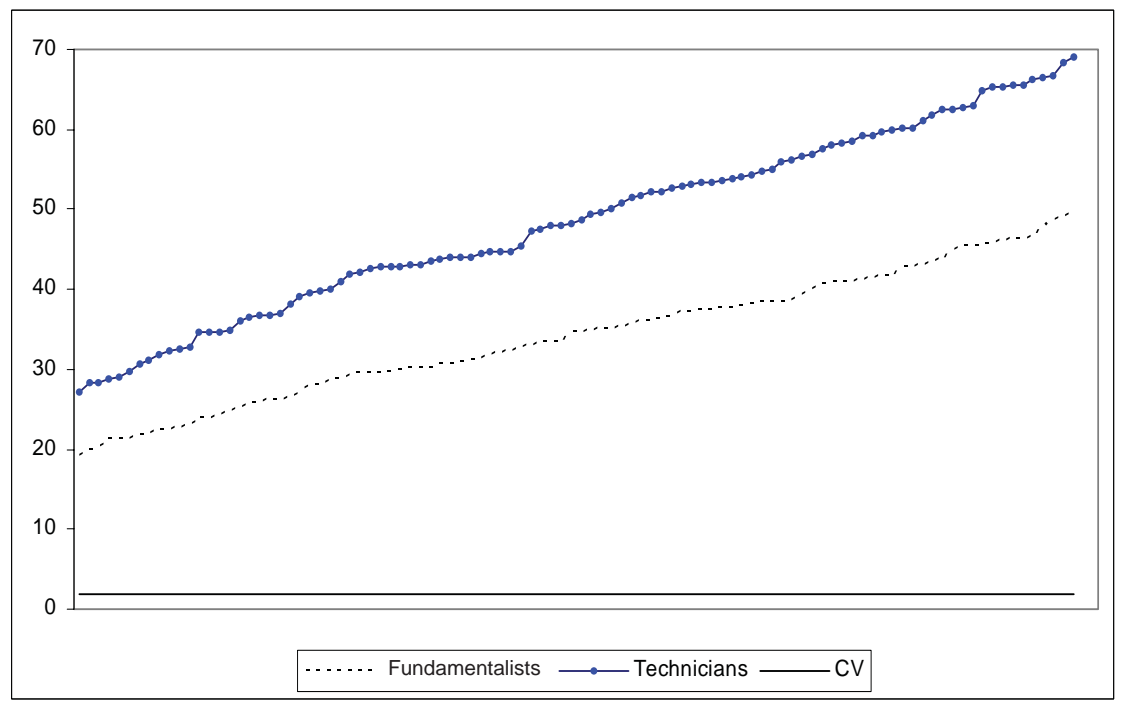

(b) The Sorted $\mathrm{t}$ Statistics of the Coefficients on the Activities of Fundamentalists and Technicians with the 5\% Critical Value

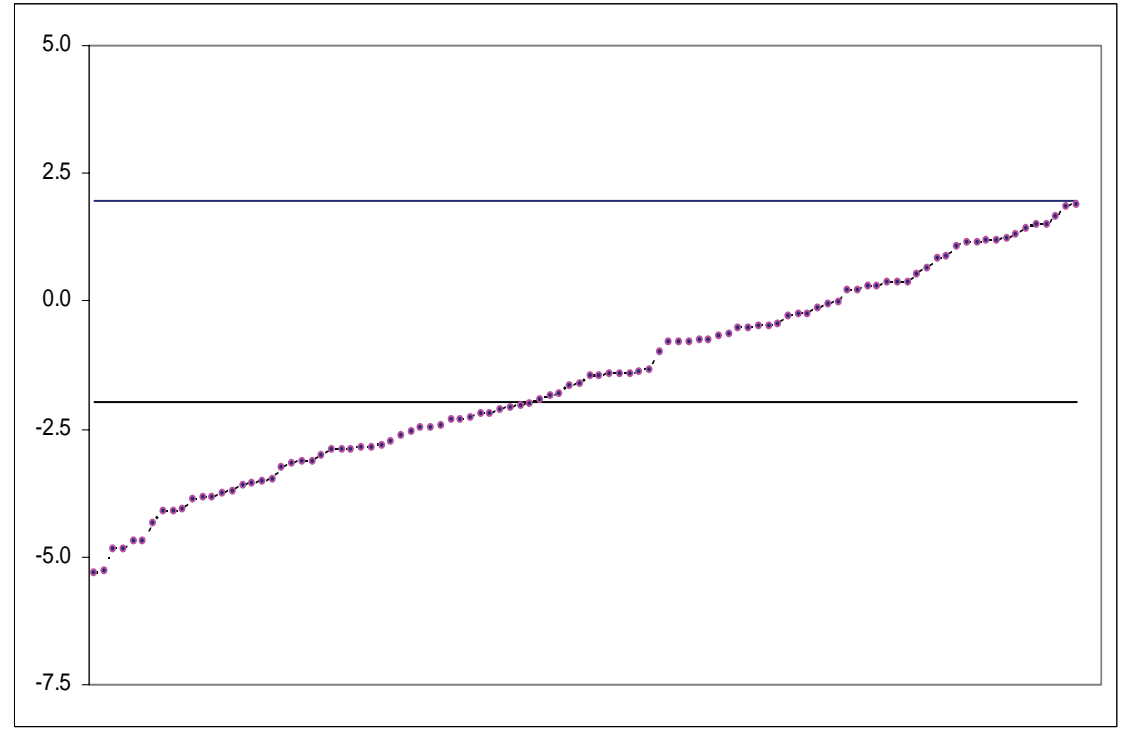

Figure 6. (Continued)

(c) The Sorted t Statistics of the Coefficient on the Government Intervention Variables with the Positive and Negative 5\% Critical Values 


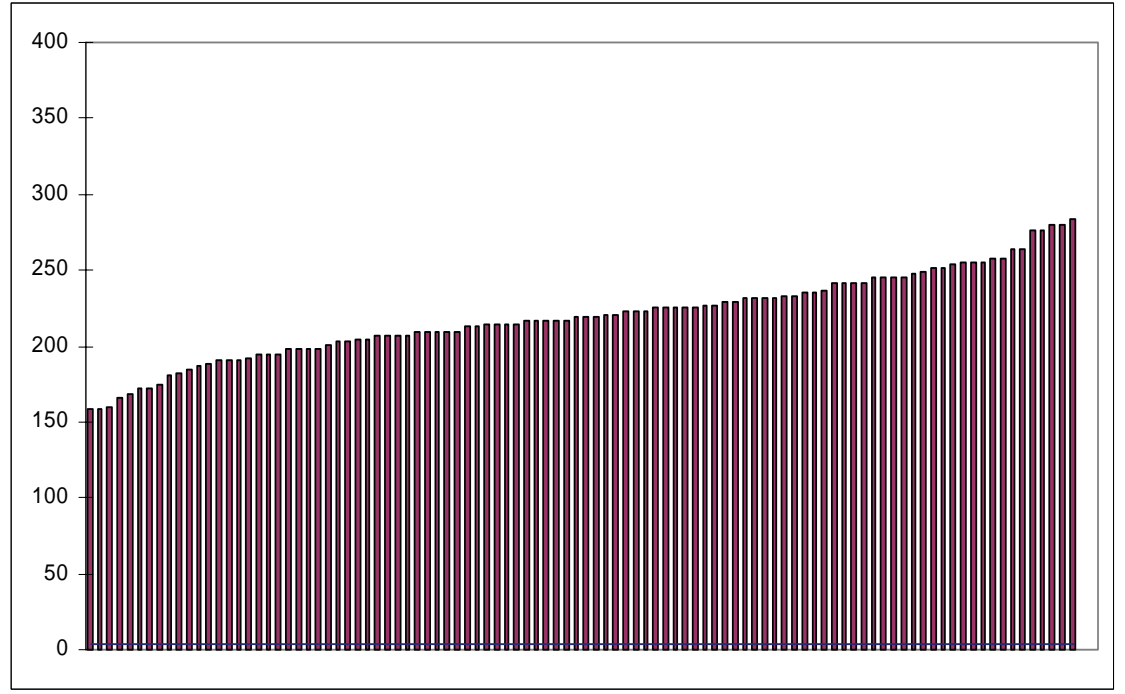

(d) The Sorted Chi-Square Test Statistics for the Equality of the Coefficients with the 5\% Critical Value

The issue that remains to be considered is whether or not the results are sensitive to company size as measured by market capitalisation. As pointed out earlier, it could be that big companies are more transparent than small companies with respect to financial reporting. If this is the case, then one would expect traders to pay more attention to fundamental factors in the case of big companies, which means that the results should favour the role of technicians less in the case of big companies. To investigate this issue we calculated the Pearson correlation coefficient between market capitalisation and the estimated coefficients $\left(\gamma_{1}, \gamma_{2}\right.$ and $\left.\gamma_{3}\right)$, their $\mathrm{t}$ statistics $\left(\mathrm{t}\left(\gamma_{1}\right), \mathrm{t}\left(\gamma_{2}\right)\right.$ and $\left.\mathrm{t}\left(\gamma_{3}\right)\right)$, and the $\chi^{2}$ statistics for the null hypothesis $\gamma_{1}-\gamma_{2}\left(\chi_{2}\left(\gamma_{1}=\gamma_{2}\right)\right.$. The results are reported in Table 4 , showing very little correlation between the results and market capitalisation. Company size, it seems, does not matter.

\section{Discussion of the Results and Concluding Remarks}

In seeking an explanation for the dominance of technicians in the Chinese stock market, one may resort to the key role played by the government, which determines how many companies can be listed each year and how many shares can be issued (Su and Fleisher, 1999). Moreover, significant proportions of the listed companies' holdings belong to the government, directly and indirectly. ${ }^{6}$

6 Gao (2002) argues that the government "seems to have too much influence on the market" by controlling IPOs and holding significant stakes in publicly-listed companies. 
Therefore, ordinary investors expect the government to be responsible for market performance. On the other hand, the government strives to achieve multiple objectives via the development of the stock market, such as improving government credibility, maintaining social stability and creating new jobs.

This means that the behaviour of the market is independent from economic fundamentals and the performance of the real sector of the economy. Figure 7 confirms this observation, showing a flat market over the period 2000-2005, followed by the surge of 2006-07, which accelerated in the first half of 2007 (before the big decline of early June). This is by no means a reflection of the performance of the Chinese economy, as it has been growing rapidly throughout the sample period.

Trading activity in the Chinese market is dominated by individual investors, because the shares controlled by the government are not traded. However, Chinese individual investors lack investment knowledge and skill in general (because they have not been in this business for long). This characteristic results in the dominance of "noise traders", who are closer to be technicians, if anything at all. As De Long et al. (1990) have shown, the behaviour of noise traders is typically unpredictable, and it can lead to a large divergence between market prices and fundamental values. Moreover, noise traders can survive for a long time and earn higher returns than sophisticated investors for bearing the extra risks created by them. ${ }^{7}$ Actually, some Chinese market anomalies can be explained by the behaviour of noise traders, including extensive speculation and excess volatility. ${ }^{8}$

7 A significant amount of work has been done on noise trading, which is defined by Black (1986) as "trading on noise as if it were information". Palomino (1996) defines noise traders as "agents with unpredictable beliefs", whereas De Long et al. (1990) them as those who "falsely believe that they have special information about the future price of risky assets". While Black (1986) does not present a reason why investors would rationally want to engage in noise trading, Trueman (1988) provides an explanation for why managers of investment funds tend to indulge in noise trading.

8 The characteristics of extensive speculation and excess volatility are examined by Gao (2002). He shows that the Chinese market exhibits exceptionally high volatility as measured by the annualised standard deviation of monthly return and the frequency, magnitude and duration of market crashes. He argues that this kind of volatility "encompasses a speculative mentality in investors who are led to make short-term bets rather than longterm investments". A measure of what Gao calls "incredible speculation" is the average annual stock turnover divided by the average market capitalisation, which he shows to be more than 500 percent (roughly ten times what is found in most developed markets). Fernald and Rogers (2002) show that the higher level of volatility of Chinese stock prices is consistent with the "simplest asset pricing model". 


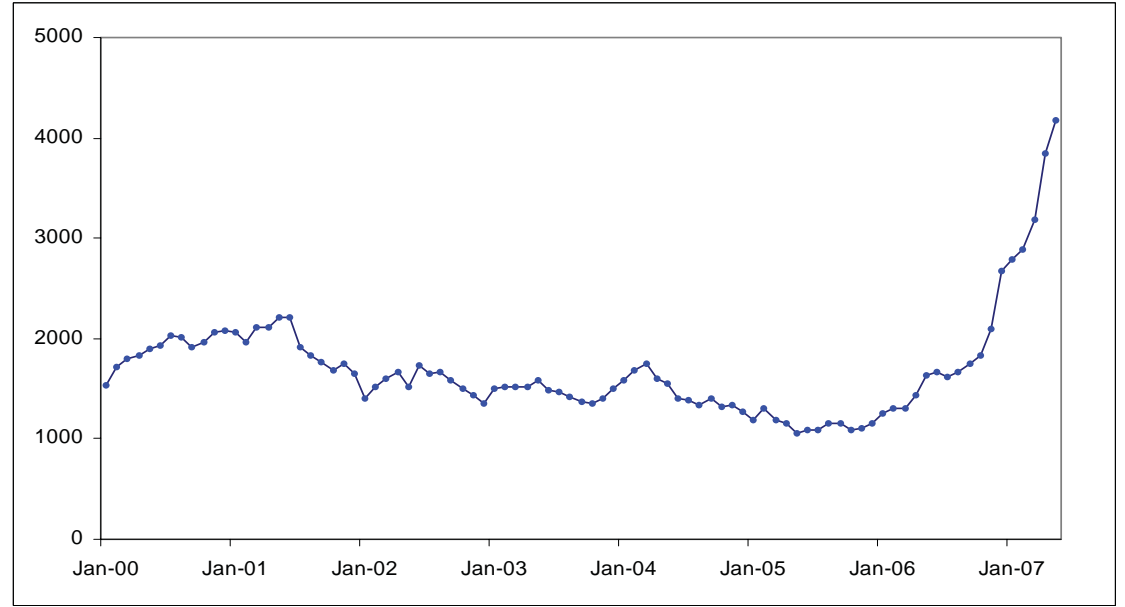

Figure 7: The Shanghai composite index

Some aspects of behavioural finance may also explain the dominance of technicians. The characteristics of the Chinese market provide fertile grounds for making investors overconfident in their judgements, the consequence of which is to overestimate the precision of information (Odean, 1998; Graham \& Harvey, 2002). Moreover, these investors appear to judge uncertain events based on their experience, which may generate representiveness bias and lead to significant divergence of market prices from the fundamental values of stocks. Confirmation bias and conservatism are also important. Confirmation bias exists when investors only believe information that supports their opinion and ignore information that does not. On the other hand, investors with conservatism bias have a relatively slow reaction to market changes because they may think that new information is irrelevant and stick to what they believed previously. All of these phenomena seem to be thriving in the Chinese stock market (see, for example, Lin, 2005).

The Chinese corporate governance system may also explain the dominance of technicians. The major shareholders in China are likely to be institutions and the state rather than individuals. Individual investors account for around 30 percent of total shares, and these shares are scattered over potentially many thousands of shareholders for each company (Hovey et al. 2003). In addition, it is very hard to find an individual shareholder on the board of directors, and it is believed that the interests of individual investors are not well protected. Therefore, Mok and Hui (1998) conclude that Chinese individual investors mainly look for the short-term capital speculation rather than long-term investment. This makes these investors more of technicians than fundamentalists.

It can be concluded, therefore, that the results presented in this paper support the established view and the available survey and econometric evidence on the roles played by fundamentalists and technicians in financial price determination. 
However, some special features of the Chinese market give the technicians the upper hand, in the sense that their activities have a more significant impact on stock prices than those of the fundamentalists.

Author statement: Imad Moosa is a professor in the Department of Accounting and Finance, Monash University, Melbourne. E-mail: imad.moosa@buseco. monash.edu.au. Larry Li is a teaching staff at the Latrobe University, Melbourne. E-mail:1.li@latrobe.edu.au. 

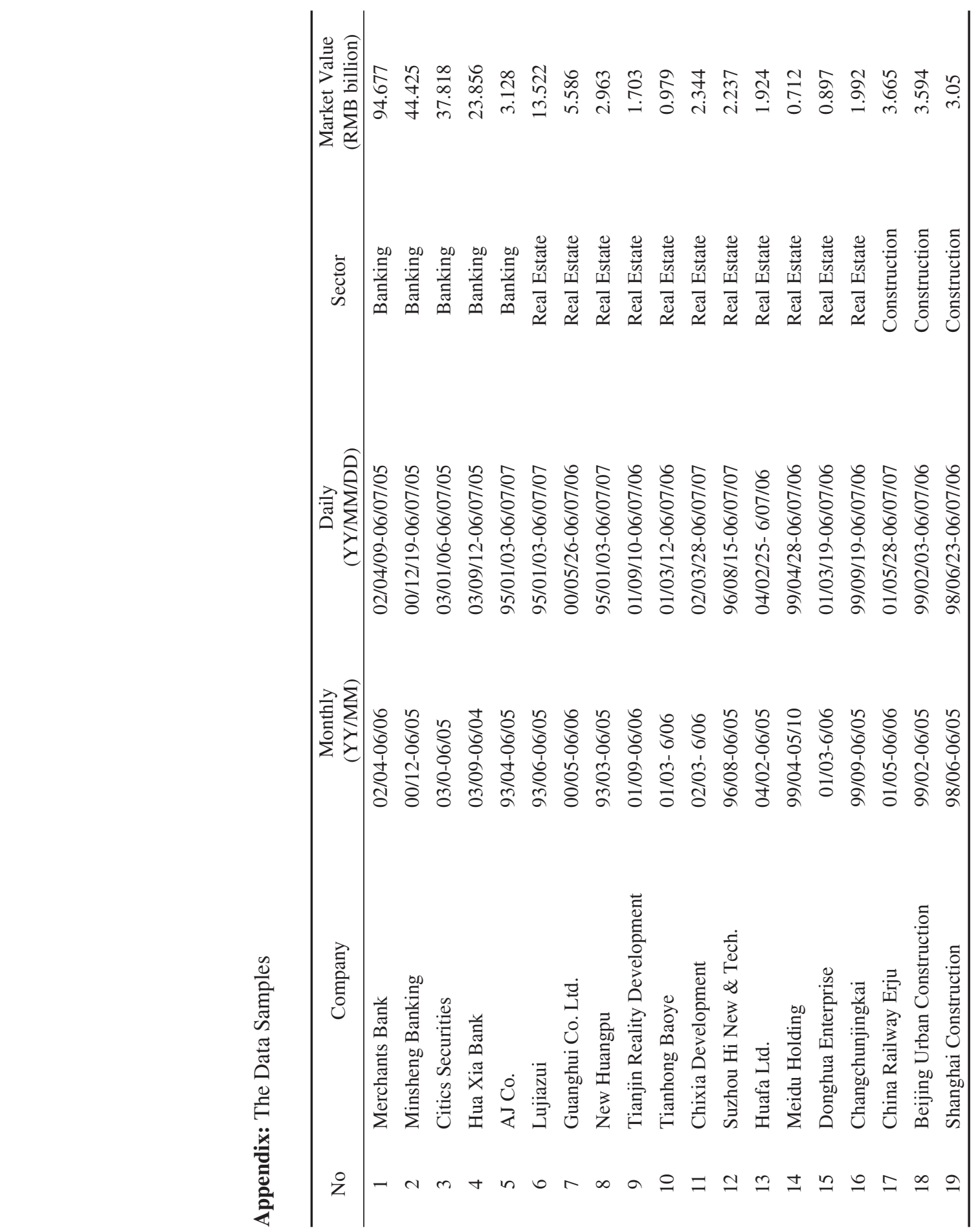
Modelling the behaviour of technicians and fundamentalists in the Shanghai Stock Market: 1-36

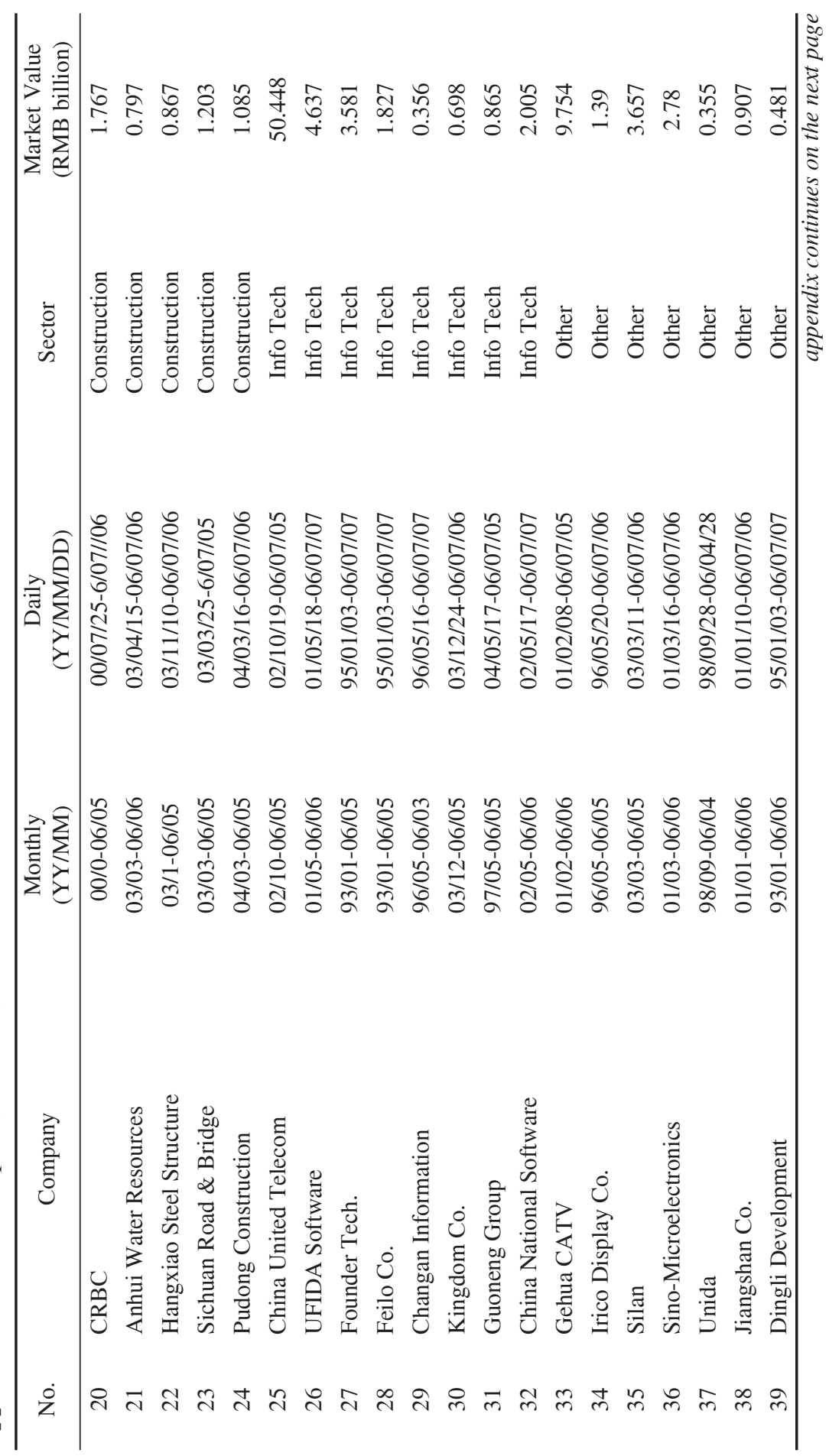



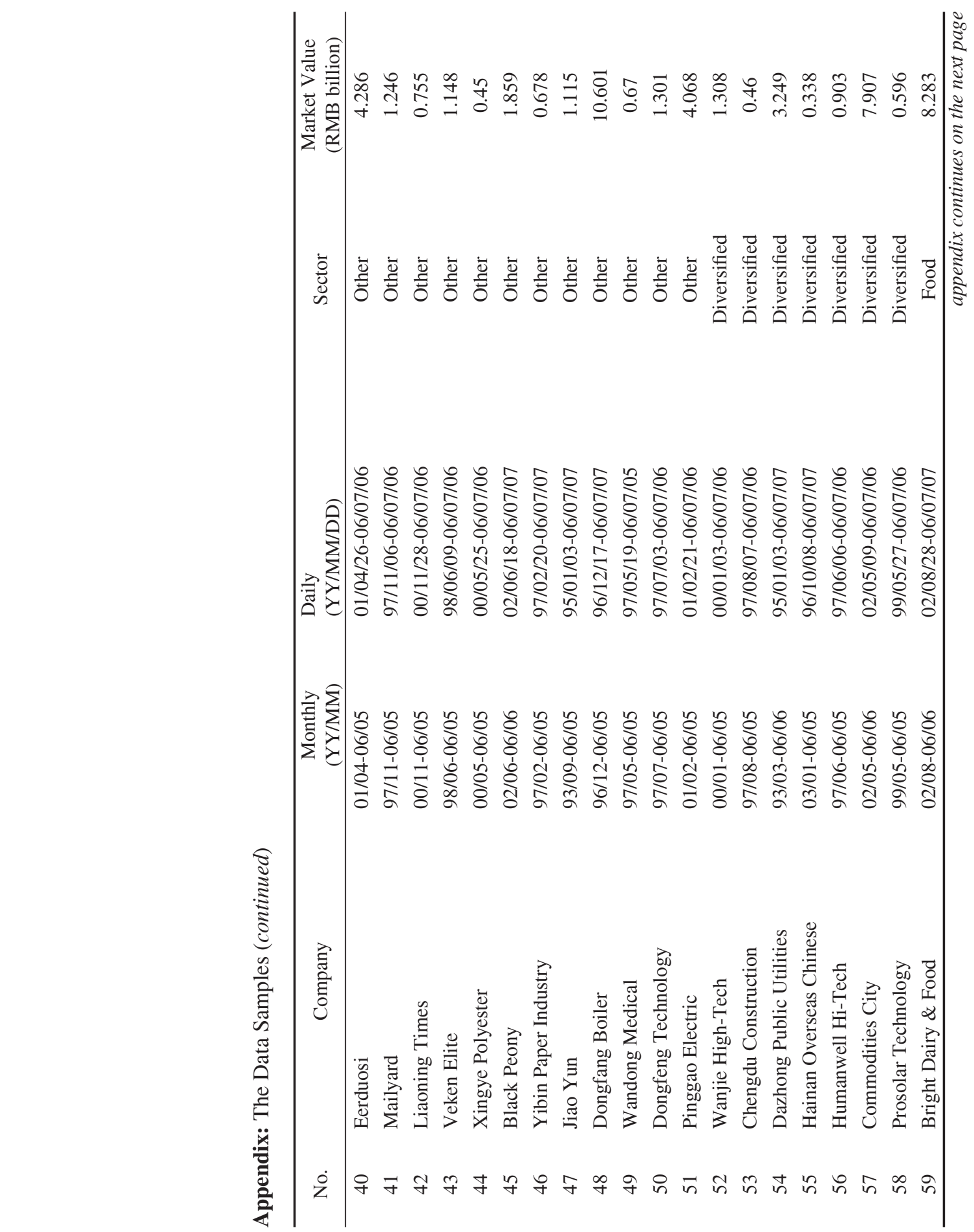

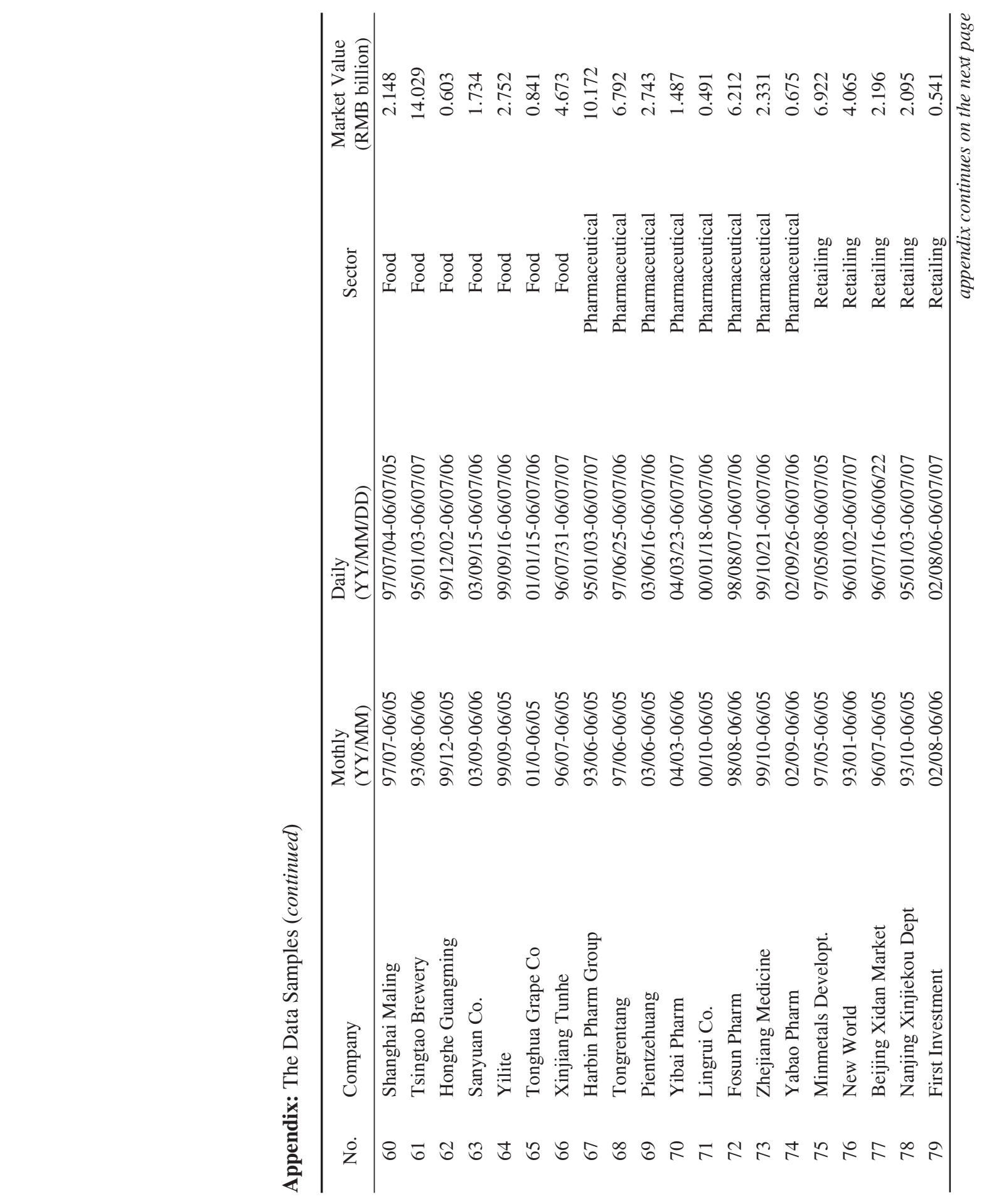

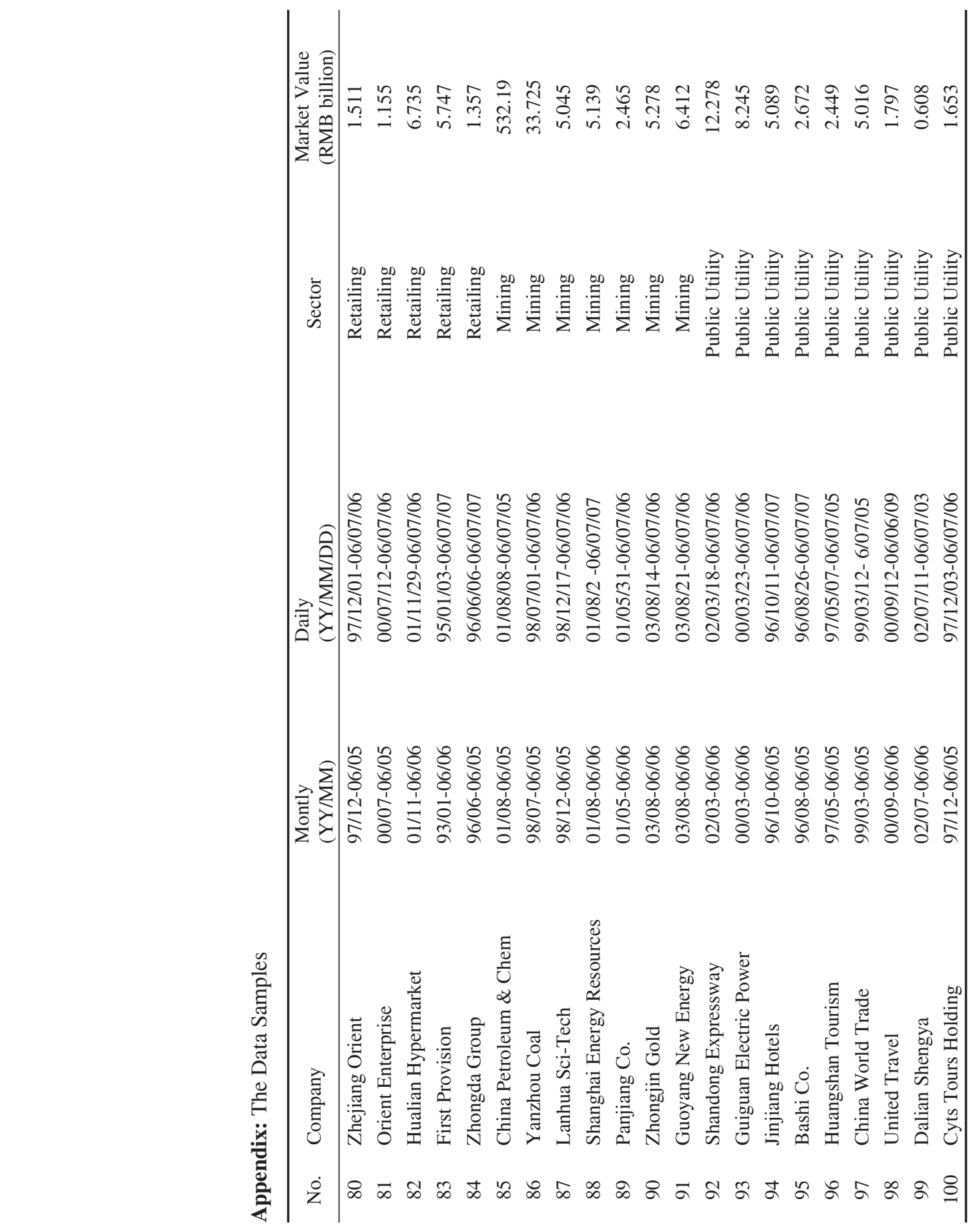


\section{References}

Al-Muraikhi, H. (2005). Speculation in Emerging Financial Markets: The Case of the Kuwait Stock and Foreign Exchange Markets (Doctoral dissertation, La Trobe University).

Black, F. (1986). Noise. Journal of Finance, 41, 529-543.

Cheung, Y-W, Chinn, M.D., and Marsh, I.W. (2004). How do UK-based exchange dealers think their market operates? International Journal of Finance and Economics, 9, 289-306.

Dastoor, N. (1983). Some aspects of testing Non-Nested Hypotheses. Journal of Econometrics, 21, 213-228.

Davidson, R., and MacKinnon, J.G. (1981). Several tests for models specification in the presence of alternative hypotheses. Econometrica, 49, 781-793.

De Long, J. B., Shleifer, A., Summers, L.H., and Waldmann, R. (1990). Noise trader risk in financial markets. Journal of Political Economy, 98, 703738.

Deaton, A. (1982). Model selection procedures, or does the consumption function exist? In Chow, G.C. and Corsi, P. (Eds), Evaluating the reliability of macroeconometric models. New York: Wiley.

Fernald, J., and Rogers, J. (2002). Puzzles in the Chinese stock market. Review of Economics and Statistics, 84, 416-432.

Fisher, G.R., and McAleer, M. (1981). Alternative procedures and associated tests of significance for non-nested hypotheses. Journal of Econometrics, $16,103-119$.

Frankel, J., and Froot, K. (1990). The rationality of the foreign exchange rate: Chartists, fundamentalists and trading in the foreign exchange market. American Economic Review, 80, 181-185.

Gao, S. (2002, Sept.) China stock market in a global perspective. Dow Jones Indexes, 1-48.

Godfrey, L.G., and Pesaran, M.H. (1983). Tests of non-nested regression models: Small sample adjustments and Monte Carlo evidence, Journal of Econometrics, 21, 133-154.

Graham, J.R., and Harvey, C. (2002). How do CFOs make capital budgeting and capital structure decisions? Journal of Applied Corporate Finance, $15,8-23$.

Guest, O. (2004). The time series properties of the spi futures market and implications for financial decisions (Doctoral dissertation, La Trobe University).

Harvey, J.T. (1993). The institution of foreign exchange trading. Journal of Economic Issues, 27, 679-698.

Hodrick, R., and Prescott E. (1997). Post-War U.S. business cycles: An empirical investigation. Journal of Money, Credit and Banking, 29, 1-16.

Hovey, M., Li., L., and Naughton, T. (2003). The relationship between valuation and ownership of listed firms in China. Corporate Governance: An International Review, 11, 112-122. 
Kirman, A. (1991). Epidemics of opinion and speculative bubbles in financial markets. In M.P. Taylor (Ed.), Money and Financial Markets, Oxford: Blackwell.

Levin, J.H. (1997). Chartists, fundamentalists and exchange rate dynamics. International Journal of Finance and Economics, 2, 281-290.

Lin, W. (2005). Manipulation, price limits and the weekend effect: A study of the Chinese stock market (Doctoral dissertation, La Trobe University).

Mizon, G.E., and Richard, J.F. (1986). The encompassing principle and its application to non-nested hypotheses. Econometrica, 54, 657-678.

Mok, H.M.K., and Hui, Y.V. (1998). Underpricing and after market performance of IPOs in Shanghai, China. Pacific-Basin Financial Journal, 6, 453-474.

Moosa, I.A. (2002). Exchange rates and fundamentals: A microeconomic approach. Economia Internazionale, 5, 551-571.

Moosa, I.A. (2003). International financial operations: Arbitrage, hedging, speculation, investment and financing. London: Palgrave.

Moosa, I., and Al-Loughani, N. (2003). The role of fundamentalists and technicians in the foreign exchange market when the domestic currency is pegged to a basket. Applied Financial Economics, 13, 79-84.

Moosa, I., and Korczak, M. (2000). The role of fundamentalists and technicians in exchange rate determination. Economia Internazionale, 53, 97-106.

Moosa, I., and Shamsuddin, A. (2003). Heterogeneity of traders as a source of exchange rate volatility: Some simulation results based on a descriptive model. Journal of Financial Studies, 11, 43-69.

Odean, T. (1998). Are investors reluctant to realize their losses? Journal of Finance, 53, 1775-1798.

Palomino, F. (1996). Noise trading in small markets. Journal of Finance, 51, $1537-1550$.

Pesaran, M.H. (1974). On the general problem of model selection. Review of Economic Studies, 41, 153-171.

Pesaran, M.H., and Pesaran, B. (1997). Working with Microfit 4.0: Interactive econometric analysis. Oxford: Oxford University Press.

Pilbeam, K. (1995a). Exchange rate models and exchange rate expectations: An empirical investigation. Applied Economics, 27, 1009-1115.

Pilbeam, K. (1995b). The profitability of trading in the foreign exchange market: Chartists, fundamentalists, and simpletons. Oxford Economics Papers, 47, 437-452.

Trueman, B. (1988). A theory of noise trading in securities markets. Journal of Finance, 43, 83-95.

Vigfusson, R. (1997). Switching between chartists and fundamentalists: A Markov regime-switching approach. International Journal of Finance and Economics, 2, 291-305. 